\title{
SEISMIC PERFORMANCE OF STEEL FRICTION CONNECTIONS CONSIDERING DIRECT-REPAIR COSTS
}

\author{
Yeow TZ, Orumiyehei A, Sullivan TJ, MacRae GA, Clifton GC, and Elwood KJ
}

\begin{abstract}
This study compares seismic losses considering initial construction costs and direct-repair costs for New Zealand steel moment-resisting frame buildings with friction connections and those with extended bolted-end-plate connections. A total of 12 buildings have been designed and analysed considering both connection types, two building heights (4-storey and 12-storey), and three locations around New Zealand (Auckland, Christchurch, and Wellington). It was found that buildings with friction connections required design to a higher design ductility, yet are generally stiffer due to larger beams being required to satisfy higher connection overstrength requirements. This resulted in the frames with friction connections experiencing lower interstorey drifts on most floors but similar peak total floor accelerations, and subsequently incurring lower drift-related seismic repair losses. Frames with friction connections tended to have lower expected net-present-costs within 50 years of the building being in service for shorter buildings and/or if located in regions of high seismicity. None of the frames with friction connections in Auckland showed any benefits due to the low seismicity of the region.
\end{abstract}

\subsection{INTRODUCTION}

The 2010-2011 Canterbury earthquakes caused major damage which led to over 1,240 buildings being demolished (as of February 2015) in the central business district (Gates 2015). However, a large proportion of steel buildings had damage that was deemed reparable and were hence reused. This has resulted in a significant uptake of steel buildings in Christchurch, with over $80 \%$ of new total floor area being supported by steel or steel-composite construction (Bruneau and MacRae 2017; MacRae and Clifton 2015). Furthermore, interviews with engineering firms by Bruneau and MacRae (2017) indicated that steel is also becoming increasingly more common in other major urban centres in New Zealand.

In addition to traditional steel frames, other structural systems currently being adopted in Christchurch include (i) nominally elastic systems, (ii) systems with buckling-restrained-braces, (iii) eccentrically braced frames with replaceable links, (iv) base isolation, and (v) rocking frame systems (Bruneau and MacRae 2017; MacRae and Clifton 2015). However, one solution rarely used in the primary lateral load resisting system are friction connections, which dissipate energy through friction instead of inelastic actions and have superior reparability compared to more traditional connections. This could be due to (i) ongoing refinement of solutions in research, (ii) industry's unfamiliarity in design approaches and application, and (iii) benefits not quantified in a manner easily understood by stakeholders.

One manner in which the benefits of adopting friction connections, or other low-damage technologies in general, can be assessed is by performing seismic loss estimation, which quantifies losses in terms of direct damage-repair costs, operational downtime, and injuries. This approach is currently used by the US Resiliency Council (2015) to give building ratings based on the likely seismic performance, with better performing buildings receiving higher ratings. Such an approach may also be useful for implementation in New Zealand practice. However, downtime 
and injuries are difficult to quantity as they are dependent on location specific variables, such as restricted access due to cordons.

This paper looks to provide insight into the relative performance and cost-effectiveness (considering difference in initial construction costs and damage-related losses) of implementing friction beam-column and column-base joints in steel moment-resisting frames against those with traditional joints. The work considers 4-storey and 12storey buildings designed to minimum requirements of New Zealand standards for Auckland, Christchurch, and Wellington. Through this research, answers to the following questions are sought:

1) How does the design of frames with friction connections differ from more traditional solutions?

2) What is the impact of using friction connections instead of traditional connections on peak inter-storey drifts and total floor accelerations?

3) What is the impact of using friction connections instead of traditional connections on seismic losses?

4) Are friction connections likely to have lower expected overall costs (including initial construction and seismic losses) within 50 years of being in service?

\subsection{BACKGROUND}

\subsection{Friction connection mechanics and experimental tests}

Friction connections are steel connections which dissipate energy through friction. These may be located at the beam-column joint (Clifton 2005; Khoo et al. 2012), column bases (Borzouie et al. 2015), eccentrically braced frame links (Leung et al. 2015), and braces (Golondrino et al. 2015). An example of friction beam-column joints and column-base joints are shown in Figures 1a and 1b, respectively, where sliding is permitted at the web and the bottom beam flange for the former and at both column flanges for the latter. Each sliding region has a flange plate with elongated holes to enable movement, a cap plate, and shims with high hardness in between each surface. Advancements in the friction connections, such as the use of Beville washers (Ramhormozian et al. 2014), have been proposed, though research is currently on-going in this regard and hence only the configuration shown in

Figure 1 is considered further.

The idealized joint behaviour without axial loading is shown in Figure 1c (MacRae et al. 2010). Here, the joint moment resistance increases from zero at rest (point a) until sliding initiates between the flange and flange plate (point b). Further moments can be resisted until sliding initiates between the cap plate and flange plate (point c), after which sliding fully occurs on both surfaces. The same occurs if the joint is loaded in the opposite direction (points $\mathrm{d}$ and e). In reality, the transition is smoother as shown by experimental results of the friction beam-column joint (Khoo et al. 2012) and the friction column base connection (Borzouie et al. 2015) in Figures 1d and 1e, respectively. Of particular interest is the column-base connection behaviour which exhibits self-centring characteristics. This is because when one of the surfaces slides when the moment demand is significant enough, the column base pivots about the opposite surface. As the axial reaction force is concentrated at this pivot point, the eccentricity between the pivot point and the centroid of the section where the axial demand force acts causes a restorative moment akin to rocking columns, resulting in the self-centring properties observed in Figure 1e. Note, however, that the shape of the column base hysteretic behaviour may not always match that shown in Figure 1e as it would depend on the ratio of the restoring moment to the moment corresponding to the friction capacity. 
Unidirectional quasi-static cycling testing of a beam-column friction connection undertaken by Clifton (2005) showed that the joint may accommodate a further 10-15 mrad of rotation after the bolts reach the end of the elongated holes before the bolts are permanently weakened, and can accommodate up to $120 \mathrm{mrad}$ of plastic rotation in total before the bottom flange plate fractures. It was noted that the top and web plates were still intact at this point which prevented complete fallout of the beam. The authors are not aware of other tests performed on the friction connections at beam-column joints or column bases to reach failure.

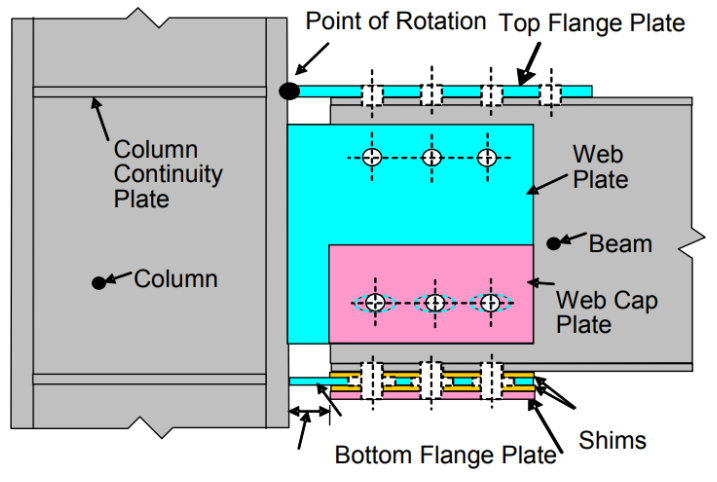

Beam Clearance Bottom Flange Cap Plate

(a)

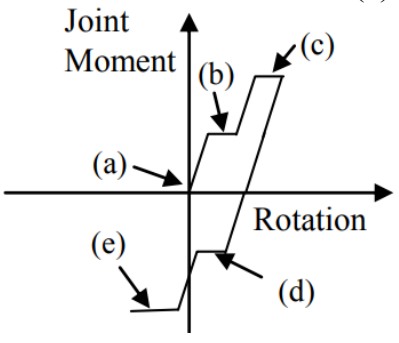

(c)

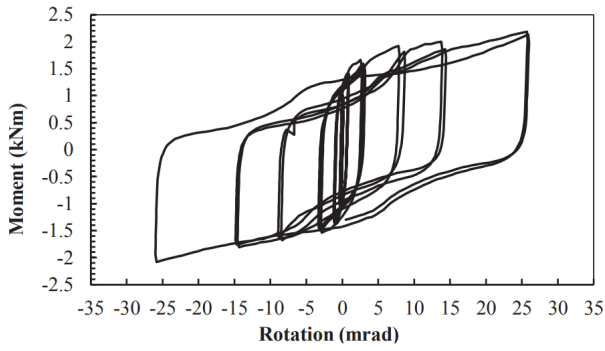

(d)

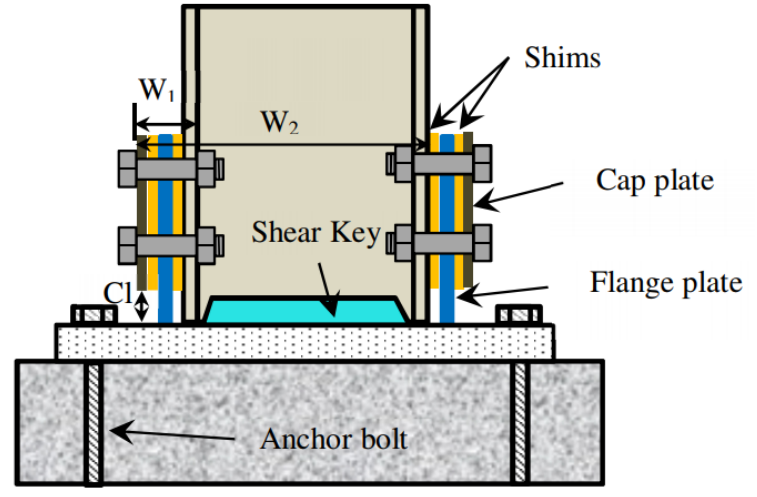

(b)

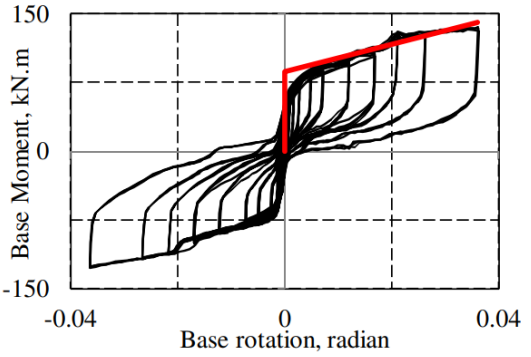

(e)

Figure 1. Friction connections examples and details; (a) example of a sliding hinge joint (MacRae et al. 2010), (b) example of a friction base connection (Borzouie et al. 2015), (c) idealized joint behaviour (MacRae et al. 2010), (d) hysteretic behaviour of sliding hinge joint (Khoo et al. 2012), and (e) hysteretic behaviour of friction base connection (Borzouie et al. 2015)

\subsection{Friction connection design}

In early designs, the sliding shear capacity between each interface of the friction connection was estimated following a model developed by Clifton (2005) based on plastic bolt theory which considers bolt axial-momentshear interaction, which was further refined by MacRae et al. (2010). However, simpler models based on an assumed friction coefficient of 0.25 have since been proposed by Khoo et al. (2015) for use in engineering practice as shown in Eq 1.

$$
V_{s s, \text { new }}=0.25 \times N_{t f} \times n_{s} \times n_{b}
$$

where $V_{s s, \text { new }}$ is the sliding shear capacity, $N_{t f}$ is the proof load of a single bolt, $n_{s}$ is the number of sliding surfaces (usually taken as two), and $n_{b}$ is the number of bolts. The flexural capacity of the joint is therefore the shear capacity of the interface multiplied by the lever arm to the point of rotation considering all sliding surfaces. A design force reduction factor and an overstrength factor of 0.7 and 1.4, respectively, are recommended (MacRae and Clifton 2015). Approaches for designing these joints are available in literature (Clifton 2002; MacRae et al. 2010), and generally consists of (i) selecting the number and size of bolts such that the flexural capacity of the joint is greater than the design demand, then (ii) designing other plates and welds in the joint, as well as beams 
and columns, to withstand the overstrength action of the friction connection. The joint is also designed to enable a "plastic" rotation of $37.5 \mathrm{mrad}$ before the bolts reach the end of the elongated holes.

\subsection{Friction connection modelling}

Hysteretic models of the sliding hinge joint have been proposed by Clifton (2005) and Khoo (2013), and the general behaviour is depicted in Figure 2.

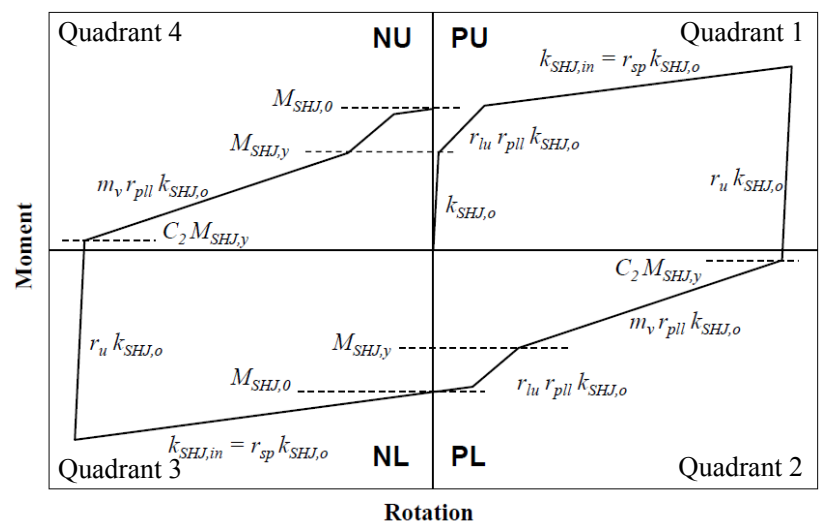

Figure 2. Proposed hysteretic model for the sliding hinge joint connection (Khoo 2013)

The elastic, post-first yield, and fully inelastic stiffnesses $\left(k_{S H J, o}, k_{S H J, p y}\right.$, and $k_{S H J, i n}$, respectively) can be calculated from Eqs. 2 to 6.

$$
\begin{aligned}
& \Delta_{l}=\frac{n_{b f b} V_{s s, o l d} l_{b f p}}{b_{b f p} t_{b f p} E} \\
& \theta_{S H J, y}=\frac{\Delta_{l}}{2 d_{b}} \\
& k_{S H J, o}=\frac{0.67 M_{S H J, y}}{\theta_{S H J, y}} \\
& k_{S H J, p y}=r_{l u} r_{p l l} k_{S H J, o}=3.5 \times \frac{1.45 M_{S H J, y}}{0.03} \\
& k_{S H J, i n}=r_{s p} k_{S H J, o}=0.007 k_{S H J, o}
\end{aligned}
$$

where $\Delta_{l}$ is the estimated elongation of the bottom flange plate once the sliding force has been reached, $n_{b f b}$ is the number of bottom flange bolts, $V_{\text {Ss,old }}$ is the sliding shear capacity obtained from plastic bolt theory (Clifton 2005; MacRae et al. 2010), $l_{b f p}$ is the longitudinal distance from the point of rotation to the centroid of sliding bolts, $b_{b f p}$ is the width of the bottom flange plate, $t_{b f p}$ is the thickness of the bottom flange plate, $E$ is the Young's modulus of steel, and $d_{b}$ is the depth of the beam. A complication here is that $V_{s s, o l d}$ and $M_{S H J, y}$ are based on the plastic bolt theory model, and that the moment capacity based on the simplified model following $\mathbf{E q} \mathbf{1}$ is more akin to $M_{S H J, 0}$. Minor modifications to the hysteretic equations are thus required if the simplified model is followed. Also note that, as there have not been many experiments where the friction connection has been tested to complete failure, the strength and stiffness degradation characteristics are not well known, and hence models to capture this effect have not been proposed for friction connections. 


\subsection{Seismic loss estimation}

One of the most widely used seismic loss estimation approaches is the Pacific Earthquake Engineering Research (PEER) centre's framework (Deierlein et al. 2003) shown in Eq. 7.

$$
\lambda(D V)=\iiint G\langle D V \mid D M\rangle d \cdot G\langle D M \mid E D P\rangle \cdot d G\langle E D P \mid I M\rangle \cdot d \lambda(I M)
$$

where $I M$ is the intensity measure (i.e. measure of ground shaking); $E D P$ is the engineering demand parameter (i.e. building response); $D M$ is the damage measure (i.e. measure of the component damage); $D V$ is the decision variable (i.e. losses); $\lambda(D V)$ and $\lambda(I M)$ are the annual rates of exceeding a given value of $D V$ and $I M$, respectively; and $G\langle D V \mid D M\rangle, G\langle D M \mid E D P\rangle$ and $G\langle E D P \mid I M\rangle$ are probabilities of $D V, D M$, and $E D P$ conditioned to $D M$, EDP, and $I M$, respectively. Loss estimation is performed in four key stages; (i) probabilistic seismic hazard analyses to derive $\lambda(I M)$, (ii) structural analyses using ground motions consistent with the seismic hazard to estimate $G\langle E D P \mid I M\rangle$, (iii) use of fragility functions to obtain $G\langle D M \mid E D P\rangle$, and (iv) use of loss distributions, $G\langle D V \mid D M\rangle$, to predict losses.

In the first iteration of the PEER framework, two main overall building damage states were considered; collapse and non-collapse. In recent years, the non-collapse damage state has been separated into (i) repairable, and (ii) demolition required. Ramirez and Miranda (2012) proposed that the need for demolition can be assessed by evaluating the residual drift response of the building. There is, however, a challenge in modelling the residual response of the steel building with friction connections, particularly at the highly non-linear range, as the strength and stiffness degradation behaviour of these connections are not currently known. An alternate approach as described in ATC-58 (Applied Technology Council 2012a; Applied Technology Council 2012b) is to apply a threshold repair cost value, where if the calculated repair cost is greater than this value then repairs are deemed uneconomical. It was also observed during the 2010-11 Canterbury earthquakes that a significant number of buildings were demolished due to financial reasons despite there being small residual drifts (Cooper et al. 2012b; Elwood et al. 2015), and hence the latter approach is likely to govern particularly in regions where a high proportion of buildings have insurance.

Several computer programs are available to perform steps (iii) and (iv), such as the Seismic Loss Assessment Tool, SLAT (Bradley 2011b), the Performance Assessment Calculation Tool, PACT (Applied Technology Council 2012a; Applied Technology Council 2012b), and the Seismic Performance Prediction Program, SP3 (Haselton and Baker 2017); the former two of which are freeware programs. Of these two, PACT has a larger fragility database and is able to consider the need for demolition either by (i) considering residual drifts (Ramirez and Miranda 2012), or (ii) setting a replacement cost threshold. However, an advantage of SLAT is that it computes losses following the Magnitude-orientated Adaptive Quadrature (MAQ) approach (Bradley et al. 2009b) which is less computationally demanding compared to the Monte Carlo simulation approach used by PACT. Equations to compute probabilistic seismic losses which SLAT is based on are available in Bradley et al. (2009a).

\subsection{METHODOLOGY}

\subsection{Case study building design}


The layout of the case study buildings adopted in this study was defined following discussions with industry, and is shown in Figure 3. The plan dimensions are $40 \mathrm{~m}$ by $24 \mathrm{~m}$ for the four storey building (see Figure 3a), and 48 $\mathrm{m}$ by $32 \mathrm{~m}$ for the 12-storey building. All buildings are designed with a perimeter lateral load resisting frame along each side of the building, and interior gravity beams and columns (see Figure 3b). All buildings have floor heights of $4.5 \mathrm{~m}$ on the ground floor and $3.6 \mathrm{~m}$ on all other floors. The bay width for Auckland buildings is taken as $12.0 \mathrm{~m}$ due to the lower seismicity of the region, while Christchurch and Wellington buildings have $8.0 \mathrm{~m}$ bay widths (see Figure 3c).

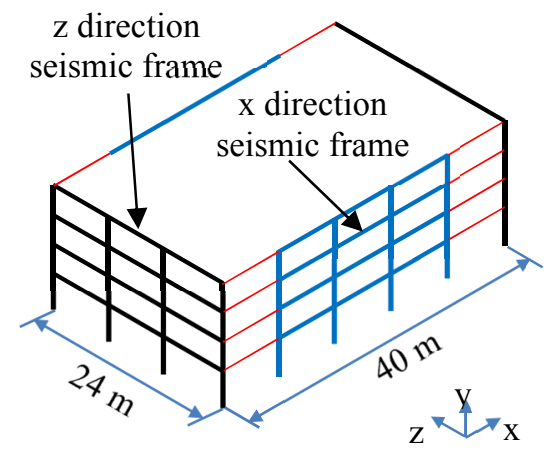

(a)

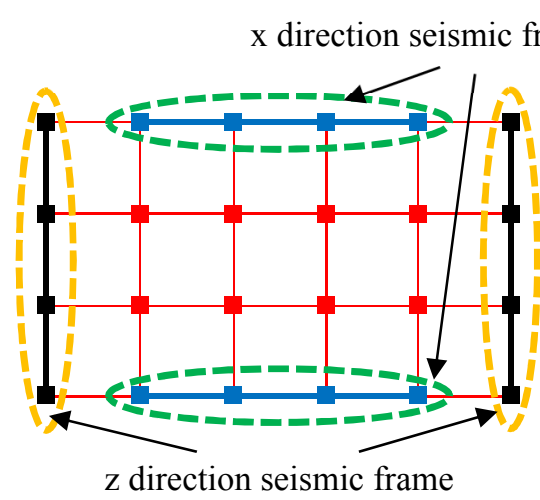

(b)

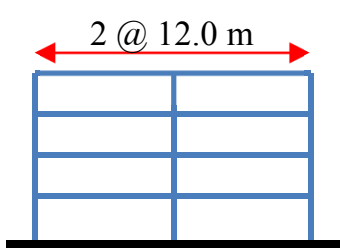

Auckland

4-storey

2 @ $12.0 \mathrm{~m}$

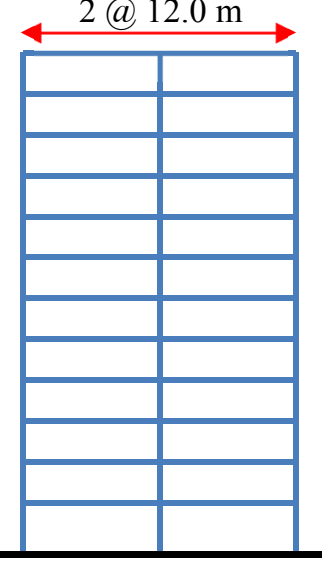

Auckland

12-storey

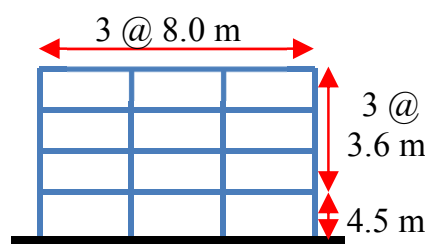

Christchurch/Wellington 4-storey

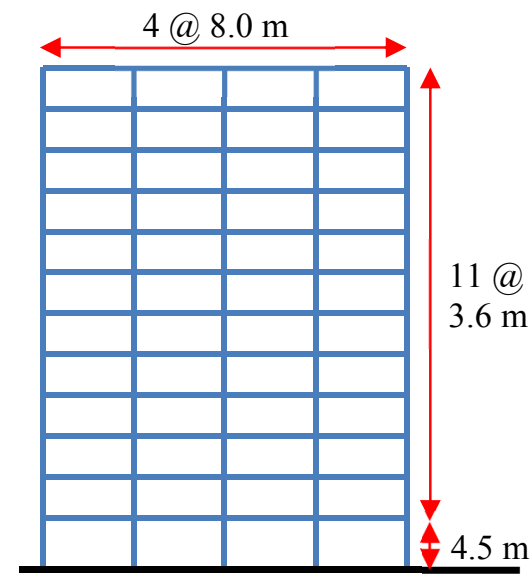

Christchurch/Wellington 12-storey

(c)

Figure 3. Case study buildings; (a) example of 4-storey isometric view, (b) example of plan view, and (c) frame elevations

The demands on the frames were obtained from New Zealand design actions standard series NZS1170 (Standards Australia and Standards New Zealand 2002; Standards Australia and Standards New Zealand 2011; Standards New Zealand 2002; Standards New Zealand 2004), while design of the structural elements followed the New Zealand steel structures standard NZS3404 (Standards New Zealand 1997). An iteration process was adopted to obtain the lightest steel frame possible while satisfying minimum standards. This involved guessing the initial size of the frame, then checking (i) serviceability drift requirements under wind actions, (ii) serviœability drift requirements under earthquake actions, (iii) ensuring that the $2.5 \%$ interstorey drift limit underultimate limit state seismic actions is not exceeded, and (iv) satisfying strength requirements under ultimate limit state gravity, wind and earthquake actions. One further consideration adopted was to only vary the beam section sizes every three floors as commonly done in practice to make construction easier. The exception to this was for the top three floors of all buildings where the beam was varied every floor to ensure that the top floor beams did not have a moment capacity to demand ratio significantly larger than those on lower floors. The frame sizes were modified until all requirements were met, and the frame size could not be decreased further. 
Two connection types are considered in the design; (i) a "traditional connection" which was taken as an extended bolted-end-plate connection as it is the most common type used in New Zealand, and (ii) friction connections at the beam-column joint and the column-base. The selected section sizes for all Auckland buildings are governed by wind serviceability requirements, and were designed with an inelastic spectrum scaling factor, $k_{\mu}$, of 1.5 or less for ultimate limit state seismic loading.

For the traditional solution in Christchurch and Wellington, the governing factor was the $2.5 \%$ drift requirement under ultimate limit state seismic actions, and the beam is designed to be the weakest link in the strength hierarchy. The design drifts for these buildings are reasonably uniform along their height due to the design approach adopted. Reduced beam sections (RBS) are used to limit the demands on the bolted end-plate connections. Based on the minimum allowed RBS width suggested by Cowie (2010), the largest possible $k_{\mu}$ which could be adopted for design is 3.0 using Grade 300 steel. It should be noted that design drift calculations using the design loading were increased by $10 \%$ to account for possible increase in flexibility following recommendations from Cowie (2010).

The design of frames with friction connections in Christchurch and Wellington was also mostly drift-governed. However, in this case the connections are the weak link in the strength hierarchy. Furthermore, due to the ratio of overstrength factor to design force reduction factor being 2.0 (MacRae and Clifton 2015), $k_{\mu}=4.0$ and Grade 350 steel had to be adopted for the design to be feasible while satisfying capacity design principles. This still resulted in larger beam sizes, though the use of higher steel grade did lead to less doubler plates being required at the panel zones which helped offset some cost. One interesting observation made was that both connection solutions had similar design drifts under ultimate limit state loading despite the difference in $k_{\mu}$, and is due to the $10 \%$ increase in drifts assumed in the traditional frame due to the use of the RBS. Also, while the building with friction connections was designed to a larger $k_{\mu}$, both frames have similar nominal strengths due to the smaller design factor of 0.7 being used for friction connections compared to the traditional frame which uses 0.9 .

\subsection{Structural modelling}

Two-dimensional inelastic structural analyses of all frames were performed in Ruaumoko2D (Carr 2004) using large displacement analysis to account for P-delta effects and assuming Caughey (1960) damping of 3\% on all modes. An example model layout for the building with friction joints is shown in Figure 4. Note that the effect of accidental torsion was not considered in this model, though it had to be included in design following NZS1170.5 (Standards New Zealand 2004). 


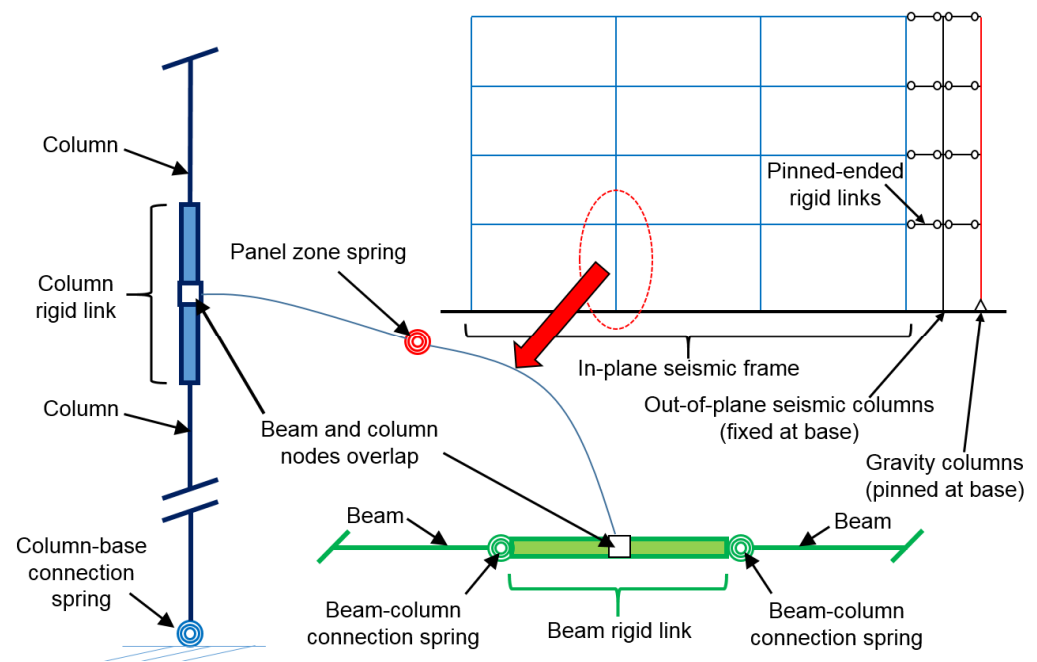

Figure 4. Modelling approach for frames with friction connections case

Rotational springs representing the friction beam-column joints, friction column-base connections, and panel zones were added at the locations shown in Figure 4. The friction beam-column behaviour shown in Figure 5a follows that outlined previously in Eqs. 2 to 6 with modifications to account for the updated bolt model (Khoo et al. 2015). The elastic rotational stiffness of the column-base connection in Figure $\mathbf{5 b}$ was assumed to be 1.67(EI/L) column based on interpretation of Clause 4.8.3.4.1 from NZS3404 (Standards New Zealand 1997) to account for base flexibility effects, and the overall behaviour was obtained by combining an inelastic bilinear hysteresis loop with an elastic bilinear curve. Note that as the ratio of the restoring force to that resulting from friction is less than 1.0, the column-base behaviour does not exhibit perfect self-centering behaviour observed in Figure 1e. The panel zone behaviour in Figure 5c follows that proposed by Kim and Engelhardt (2002) excluding kinematic hardening effects. All strengths considered in the analyses are nominal strengths. Note that while the nominal strengths prior to full in-elastic response for both the traditional frame and those with the friction connections are similar, the frame with friction connections does have a pre-yield reduction in stiffness as shown in Figure 2 and Figure 5a.

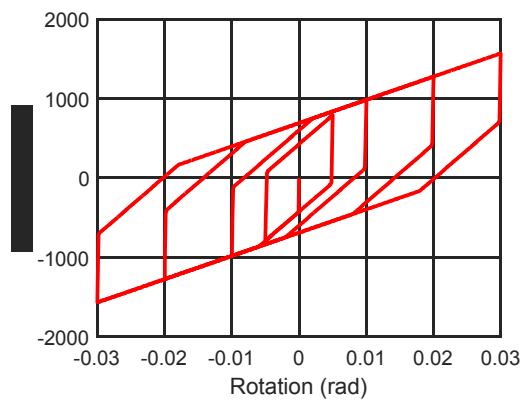

(a)

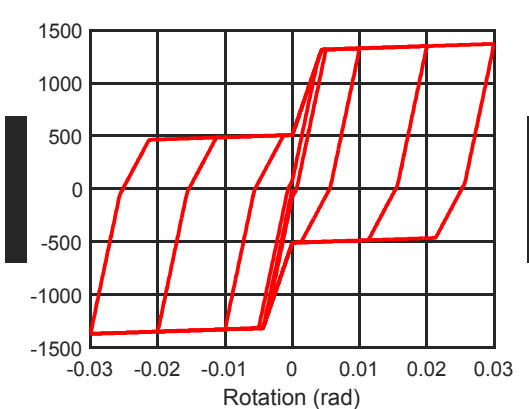

(b)

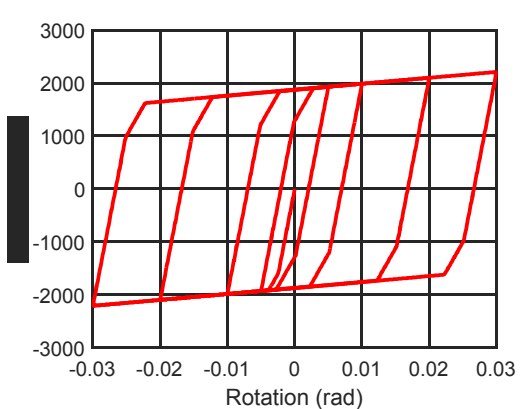

(c)

Figure 5. Example of adopted hysteresis models; (a) beam-column connection (level 1), (b) column-base connection, and (c) panel zone

The model used for the traditional frames is similar to that shown in Figure 4, with the difference being that the beam rotational springs are placed at the centroid of the RBS rather than at the end of the beam elements. Inelastic bilinear hysteresis behaviour is assumed for the beam and column base, with the elastic rotational stiffness of the

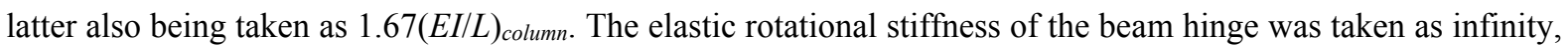
while the moment of inertia of the beam elements was reduced to approximate the reduced stiffness of the RBS. 
Flexibility of the extended bolted-end-plate connection was included in the panel zone model from Kim and Engelhardt (2002) by modifying the stiffnesses following the approach from Eurocode 3 (2009).

The fundamental mode periods of the frame models based on the adopted design and modelling approach are shown in Table 1. It can be seen that buildings with the friction connections have smaller or similar periods compared to the traditional frame due to the larger beam sizes selected to satisfy connection overstrength requirements. Note that even though the buildings in Auckland also satisfied all design criteria including allowable drifts under serviceability wind loading, the fundamental mode period for the buildings in Auckland are particularly long. Dynamic structural analysis under wind loading was not performed in this study, and hence real buildings in Auckland may be required to have greater stiffness than those examined here. Nonetheless, the relative seismic performance of the frame solutions can still be compared here.

Table 1. Building fundamental mode periods

\begin{tabular}{|c|c|c|c|c|}
\hline & \multicolumn{2}{|c|}{ 4-storey building } & \multicolumn{2}{c|}{ 12-storey building } \\
\hline Location & $\begin{array}{c}\text { Traditional } \\
\text { frame }\end{array}$ & $\begin{array}{c}\text { Friction } \\
\text { connections }\end{array}$ & $\begin{array}{c}\text { Traditional } \\
\text { frame }\end{array}$ & $\begin{array}{c}\text { Friction } \\
\text { connections }\end{array}$ \\
\hline Auckland & $2.7 \mathrm{~s}$ & $2.6 \mathrm{~s}$ & $4.6 \mathrm{~s}$ & $4.6 \mathrm{~s}$ \\
\hline Christchurch & $1.4 \mathrm{~s}$ & $1.3 \mathrm{~s}$ & $2.9 \mathrm{~s}$ & $2.6 \mathrm{~s}$ \\
\hline Wellington & $1.6 \mathrm{~s}$ & $1.5 \mathrm{~s}$ & $2.9 \mathrm{~s}$ & $2.6 \mathrm{~s}$ \\
\hline
\end{tabular}

It is important to note that strength and stiffness degradation effects were not included as this behaviour is not known for friction connections once the bolt reaches the end of the elongated holes. Building collapse and residual displacements might therefore not be well captured, as while instability due to P-delta effects may still occur, actual building collapse may occur earlier had degradation been considered. An alternate approach adopted here is to impose a drift limit which, if exceeded on any floor of the building, is assumed to trigger building collapse. In FEMA356 (ASCE 2000) Table C1-3, a peak interstorey drift limit of 5\% was suggested for the collapse prevention limit state of traditional steel frame buildings, and is adopted for the drift limit approach. While this may not be directly applicable for frames with friction connections, it is likely to be conservative as the friction connections can undergo a plastic rotation of $37.5 \mathrm{mrad}$ before the bolts reach the end of the elongated hole, and another 10-15 mrad before the bolts are permanently weakened as discussed previously (Clifton 2002). It should be noted that FEMA356 (ASCE 2000) has since been replaced with ASCE41 (ASCE 2013). However, the latter only provided a descriptive drift limit rather than a drift value and as such was not considered. While this approach is less accurate compared to explicitly considering degradation, this is unlikely to affect seismic losses significantly as past studies (Aslani and Miranda 2005; Bradley et al. 2009a) have shown that the greatest contribution to expected annual losses arises from low to moderate intensity shaking seismic events where collapse is rare.

\subsection{Seismic Hazard Analysis and Ground Motion Selection}

Probabilistic seismic hazard analysis was performed for Auckland $\left(36.85^{\circ} \mathrm{S}, 174.76^{\circ} \mathrm{E}\right)$ at a shear-wave velocity to $30 \mathrm{~m}$ depth $\left(V_{s 30}\right)$ of $450 \mathrm{~m} / \mathrm{s}$, Christchurch $\left(43.53^{\circ} \mathrm{S}, 172.64^{\circ} \mathrm{E}\right)$ for $V_{s 30}=250 \mathrm{~m} / \mathrm{s}$, and Wellington $\left(41.29^{\circ} \mathrm{S}\right.$, $174.78^{\circ} \mathrm{E}$ ) for $V_{s 30}=450 \mathrm{~m} / \mathrm{s}$ on OpenSHA (Field et al. 2003) using New Zealand-specific rupture forecast models (Stirling et al. 2012) and attenuation relationships (Bradley 2013) for spectral acceleration at $2.0 \mathrm{~s}$. Spectral acceleration corresponding to this period was chosen as the conditioning intensity measure as $2.0 \mathrm{~s}$ is in-between the fundamental periods of the 4-storey and 12-storey for the Christchurch and Wellington buildings, though it is 
on the low side for Auckland buildings. The resulting seismic hazard curves are shown in Figure 6, where the Auckland and Christchurch's seismic hazards are notably lower than the design hazard in NZS1170.5 (Standards New Zealand 2004). The low seismicity for the Auckland region is acknowledged in NZS1170.5 (Standards New Zealand 2004), which imposed a minimum hazard factor $Z$ of 0.13 to reduce the risk of collapse in moderate earthquake shaking (Mw6.5 rupture located $20 \mathrm{~km}$ from the site). For Christchurch, reasons for differences include (i) the ground motion prediction equation which NZS1170.5 (Standards New Zealand 2004) is based off overestimating the effect of small-to-moderate earthquakes (Cooper et al. 2012a), and (ii) simplification of the spectral curve shape in NZS1170.5 (Standards New Zealand 2004) which resulted in an overestimate of up to $50 \%$ for subsoil class C conditions (subsoil class D effects not known) (McVerry 2003).

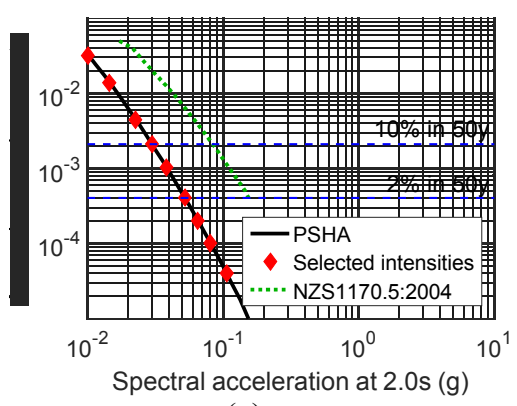

(a)

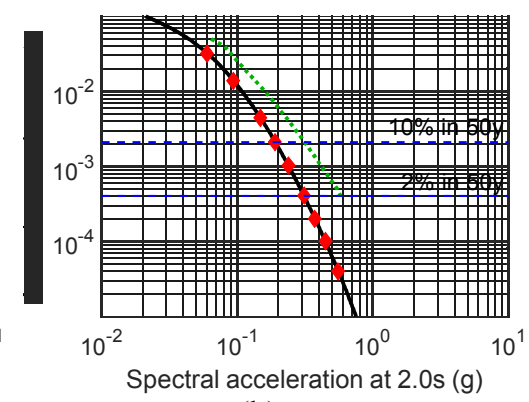

(b)

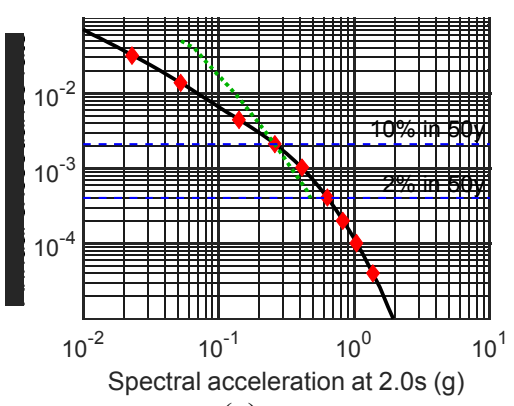

(c)

Figure 6. Comparison of probabilistic seismic hazard with NZS1170.5:2004 for (a) Auckland Sa(2.0s) subsoil class C, (b) Christchurch $\mathrm{Sa}(2.0$ s) subsoil class D, and (c) Wellington $\mathrm{Sa}(2.0 \mathrm{~s})$ subsoil class C

The generalized conditioning intensity measure approach (Bradley 2010; Bradley 2012a) is adopted for ground motion selection to ensure that the selected records are probabilistically consistent with the seismic hazard. This approach ensures that building response-hazard or loss-hazard results are consistent regardless of the selected conditioning intensity measure (Bradley 2012b). Other intensity measures, ground motion prediction equations, correlation relationships, and weighting factors adopted in the procedure are shown in Table 2. This process was performed at nine separate hazard levels ranging from $80 \%$ to $0.2 \%$ probability of exceedance in 50 years which are indicated by markers in Figure 6.

Table 2. Adopted intensity measures, ground motion prediction equations and correlation relationships

\begin{tabular}{|c|c|c|c|c|}
\hline \multicolumn{2}{|c|}{ Intensity measures } & $\begin{array}{c}\text { Ground motion prediction } \\
\text { equation }\end{array}$ & Correlation Relationship & $\begin{array}{l}\text { Weighting } \\
\text { factor }\end{array}$ \\
\hline \multirow{12}{*}{ Spectral acceleration } & $0.05 \mathrm{~s}$ & \multirow{14}{*}{$\begin{array}{l}\text { Bradley }(2013) \\
\text { for active shallow faults and } \\
\text { volcanic regions }\end{array}$} & \multirow{12}{*}{$\begin{array}{l}\text { Baker and Jayaram (2008) } \\
\text { for active shallow faults } \\
\text { and volcanic regions } \\
\text { Goda and Atkinson (2009) } \\
\text { for subduction zone } \\
\text { regions }\end{array}$} & \multirow{14}{*}{$\begin{array}{l}0.047 \text { each, } \\
0.70 \\
\text { combined }\end{array}$} \\
\hline & $0.1 \mathrm{~s}$ & & & \\
\hline & $0.2 \mathrm{~s}$ & & & \\
\hline & $0.3 \mathrm{~s}$ & & & \\
\hline & $0.5 \mathrm{~s}$ & & & \\
\hline & $0.75 \mathrm{~s}$ & & & \\
\hline & $1.0 \mathrm{~s}$ & & & \\
\hline & $1.5 \mathrm{~s}$ & & & \\
\hline & $3.0 \mathrm{~s}$ & & & \\
\hline & $4.0 \mathrm{~s}$ & & & \\
\hline & $5.0 \mathrm{~s}$ & & & \\
\hline & $7.5 \mathrm{~s}$ & & & \\
\hline \multicolumn{2}{|c|}{ Peak ground acceleration } & & \multirow{5}{*}{ Bradley (2011a) } & \\
\hline \multicolumn{2}{|c|}{ Peak ground velocity ${ }^{\mathrm{a}}$} & & & \\
\hline \multirow{2}{*}{\multicolumn{2}{|c|}{$\begin{array}{l}\text { Significant duration } 5-75 \%^{\mathrm{a}} \\
\text { Significant duration } 5-95 \%^{\mathrm{a}}\end{array}$}} & \multirow{2}{*}{ Kempton and Stewart (2006) } & & 0.1 \\
\hline & & & & 0.1 \\
\hline \multicolumn{2}{|c|}{ Cumulative absolute velocity $^{\mathrm{a}}$} & Campbell and Bozorgnia (2010) & & 0.1 \\
\hline
\end{tabular}

a intensity measures considered only for Christchurch 
The spectral acceleration curve of the $10 \%$ in 50 year ground motion suites are shown in Figures $7 \mathbf{a}$ to $7 \mathbf{c}$ for Auckland, Christchurch, and Wellington, respectively. It can be seen that Wellington's records have the largest spectral accelerations, followed by Christchurch then Auckland, which is consistent with the seismic hazard curves shown in Figure 6. One further observation is that the design spectra from NZS1170.5 are generally greater than the acceleration spectra of the ground motion records for Auckland and Christchurch, which is also consistent with observations from Figure 6. Furthermore, the spectral shape of the records, which is the spectral accelerations normalized by the spectral acceleration at $2.0 \mathrm{~s}$, are noticeably different with the design spectra as shown in Figures 7d to 7f for Auckland, Christchurch, and Wellington, respectively. In particular, the spectral shape of most records for Wellington (Figure 7f) are larger than that of the design spectra between $0.3 \mathrm{~s}$ and $2.0 \mathrm{~s}$, which indicates that higher-order effects are likely to be more pronounced using the records compared to that observed in design. Ground motion details are provided on the QuakeCore wiki page specific to this project (link in acknowledgements).

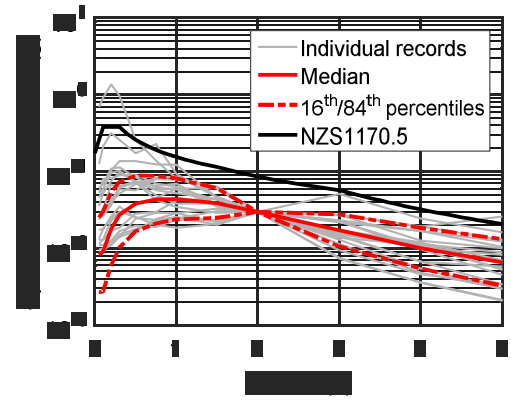

(a)

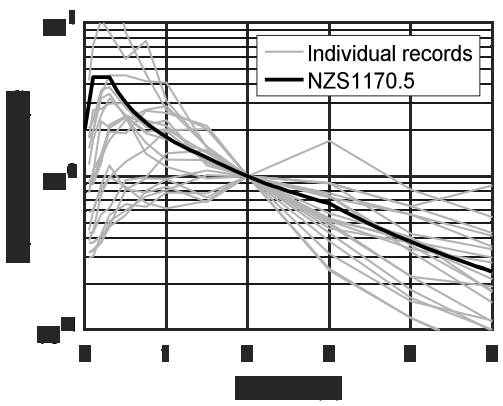

(d)

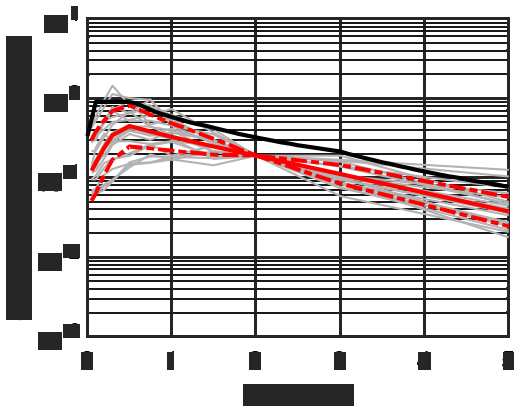

(b)

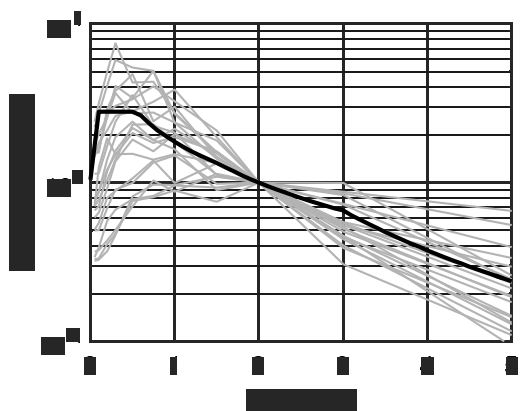

(e)

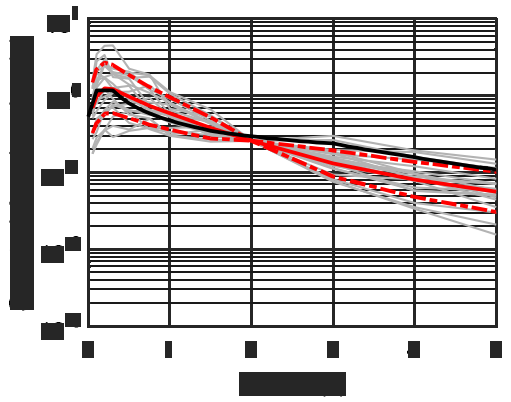

(c)

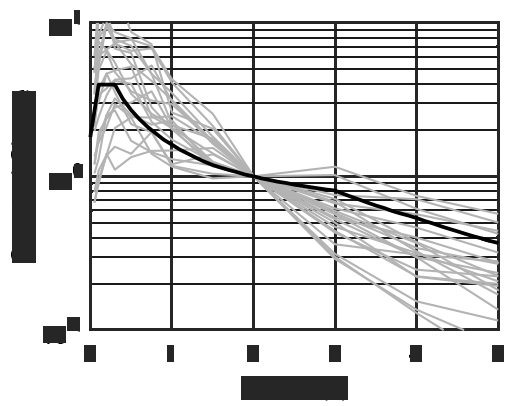

(f)

Figure 7. 10\% probability of exceedance in 50 year ground motion suite for (a) Auckland subsoil class C, (b) Christchurch subsoil class D, and (c) Wellington subsoil class C; and spectral shape comparisons for (d) Auckland subsoil class C, (e) Christchurch subsoil class D, and (f) Wellington subsoil class C

\subsection{Seismic loss estimation calculation}

Seismic loss estimation was performed on SLAT (Bradley 2011b) due to the lower computational demand required, particularly for running analyses of taller buildings. The full list of component quantities (including structural components, non-structural drift sensitive components, and non-structural acceleration sensitive components), fragility functions, and consequence functions adopted in this study are provided on the QuakeCore wiki page specific to this project (link in acknowledgements). The quantities were obtained either by (i) basing it off the designed building dimensions, (ii) reviewing plans of similar building types and usage in Christchurch, and (iii) using PACT's (Applied Technology Council 2012a; Applied Technology Council 2012b) “Normative Quantity Estimation Tool" where information was not readily available elsewhere. 
Fragility functions were obtained from literature or from PACT's (Applied Technology Council 2012a; Applied Technology Council 2012b) fragility library. The only component for which no fragility functions currently exist are friction connections. Based on the opinion of the co-authors of this paper who are extensively researching the behaviour of the friction connections, four main damage states were identified and are described in Table 3. Description of damage and repair strategies for damage states 1 to 3 are loosely based on observations from experimental tests by Clifton (2005). An additional "damage" state is introduced to account for post-earthquake inspections, where non-structural elements may have to be removed to allow for inspection of the connections. This is assumed to coincide with moderate damage to partitions, for which the fragility function was obtained from Retamales et al. (2013). This additional damage state was also added to moment-end plate connections for fair comparisons. As damage state 3 likely occurs only after 5\% interstorey drift, where the building would be deemed to have collapsed before this point, this damage state was not considered further. A dispersion of 0.4 was assumed for the fragilities for damage states 1 and 2 based on recommendations by Porter et al. (2006), and was also applied to the loss values due to a lack of information for cost estimates.

Table 3. Friction connection fragility and consequence function

\begin{tabular}{|l|l|l|l|l|}
\hline $\begin{array}{l}\text { Damage } \\
\text { state }\end{array}$ & Damage & Repair & $\begin{array}{l}\text { Median } \\
\text { EDP }\end{array}$ & $\begin{array}{l}\text { Median loss per } \\
\text { connection in NZD } \\
\text { (1-sided/2-sided) }\end{array}$ \\
\hline 0 & $\begin{array}{l}\text { Possible bolt } \\
\text { movement }\end{array}$ & $\begin{array}{l}\text { Inspect connections (assume 25\% chance of } \\
\text { connection being checked) }\end{array}$ & 0.67 & $5600 / 7980$ \\
\hline 1 & $\begin{array}{l}\text { Loosening of } \\
\text { bolts during } \\
\text { shaking }\end{array}$ & $\begin{array}{l}\text { Inspect connections, remove, lubricate, and } \\
\text { reinsert bolts (assume 50\% chance of } \\
\text { connection being checked) }\end{array}$ & 1.5 & $7000 / 9380$ \\
\hline 2 & $\begin{array}{l}\text { Bolts and shims } \\
\text { damaged } \\
\text { beyond repair }\end{array}$ & $\begin{array}{l}\text { Inspect all connections, remove and replace } \\
\text { shims and bolts if required }\end{array}$ & 3.0 & $7280 / 9800$ \\
\hline 3 & $\begin{array}{l}\text { Bottom flange } \\
\text { plate fracture }\end{array}$ & $\begin{array}{l}\text { Remove bolts and shims, flame cut and } \\
\text { remove bottom flange plate from column, } \\
\text { smoothen surface of column, weld on new } \\
\text { flange plate, reassemble shims and bolts. }\end{array}$ & $>5.0$ & - \\
\hline
\end{tabular}

The need for demolition was estimated by applying a repair cost to initial construction cost ratio of 0.4 . This was performed during post-processing of the SLAT outputs, as the program was not capable of including this effect in the assessment at the time of writing. It is assumed that the cost resulting from demolitions is equal to the building's full replacement cost.

The building's value is required to perform net-present-cost (NPC) analyses and to estimate full-replacement costs (assumed to be $20 \%$ greater than the building value). The total value of each building considered in this study is shown in Table 4. These were estimated using Rawlinson's (2015) construction handbook, which provided different cost estimates for different regions within New Zealand. This involved estimating the cost of structural components, partitions, cladding, and ceilings using quantities outlined in the QuakeCoRE wiki page (link in acknowledgements), and then adding on per square meter costs for other components as their quantities or detailing are not as well understood. It is assumed here that the cost of a friction connection itself is similar to that of a moment-end-plate connection based on discussions with industry which indicated that they are slightly cheaper to fabricate and cost a similar amount to erect. All non-structural component quantities are assumed to be consistent regardless of the structural system type, and as such the only difference in costs between the two building solutions of a given height and for a given location arises from the structural system itself. Interestingly, 
the cost difference between the two systems for the 12-storey building is over ten times greater compared to the 4-storey building. This is because larger sections are used to support the additional weight of the floors above, resulting in the total weight of the steel frames increasing disproportionately to the increase in total floor area.

Table 4. Building value (\$million NZD)

\begin{tabular}{|l|l|l|l|l|l|l|}
\hline \multirow{2}{*}{ Frame } & \multicolumn{3}{l}{ 4-storey } & \multicolumn{2}{l|}{ 12-storey } \\
\cline { 2 - 7 } & Auckland & Christchurch & Wellington & Auckland & Christchurch & Wellington \\
\hline Traditional & 8.315 & 8.917 & 8.222 & 39.57 & 42.56 & 39.43 \\
\hline Friction connections & 8.323 & 8.931 & 8.231 & 39.62 & 42.69 & 39.53 \\
\hline
\end{tabular}

Methods to calculate NPC are widely available in literature. The expression used by Bradley et al. (2009a) which is adopted in this paper is shown in $\mathbf{E q} \mathbf{8}$.

$$
\operatorname{NPC}(r, t)=C_{i}+\frac{\left(1-e^{-r t}\right)}{r} E A L
$$

Where $C_{i}$ can either be taken as the total value or the difference in building value, $E A L$ is the expected annual loss and is an output from SLAT (Bradley 2011b), $r$ is the discount rate, and $t$ is the duration that the building has been in service in years. $2 \%$ and $6 \%$ was considered as $r$ to consider a range of discount rates.

\subsection{COMPARISON OF BUILDING RESPONSE}

\subsection{Building response under $10 \%$ in 50 year shaking intensity level}

Figure 8 compares the drift response of the buildings when subjected to their respective 10\% probability of exceedance in 50 year ground motion suite. It can be seen that frames with friction connections generally have lower drifts on most floors, with the difference being more obvious for Wellington where the seismic intensity was the greatest out of the three regions considered. The first significant reason for this is that the buildings with friction connections are generally stiffer due to having larger beam section sizes to satisfy friction connection overstrength demands. A second important factor is that the earlier inelastic behaviour of the frame with friction connections results in greater energy dissipation earlier on, which also contributes to the reduced drifts at higher intensity levels. Thirdly, the friction connections do exhibit slight "pinching" behaviour compared to bilinear hysteresis curves, with less resistance in quadrants 2 and 4 compared to quadrants 1 and 3 . This significantly reduces the likelihood of accumulation of rotation akin to ratcheting effects.

Despite the points made above, the frames with friction connections do generally have greater drifts on the bottom floor compared to the traditional frames. This is due to the base of the columns also being detailed as a friction connection, whereas no modifications were made at the base of the frame with moment-end-plates. As such, the latter is significantly stronger and hence would undergo less column-base rotation.

One important note here is that the drifts were the largest on the upper floors for all buildings. This is because (i) the second mode effect is more pronounced using the selected ground motion suite compared to that considered in design following discussions from Figure 7, (ii) the columns are significantly stiffer and stronger than the beams which result in them behaving like cantilevers when the beams yielded, and (iii) the frames had consistent 
design interstorey drifts along their height due to the design approach adopted which causes the effects from (i) and (ii) to be even more prominent.

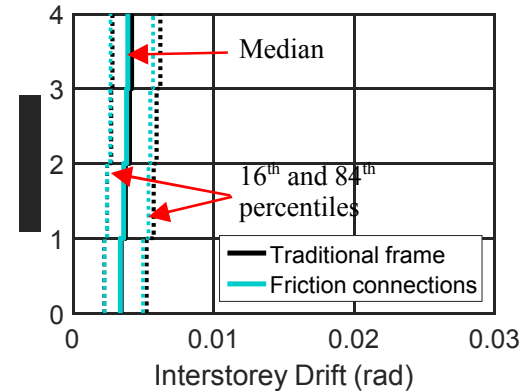

(a)

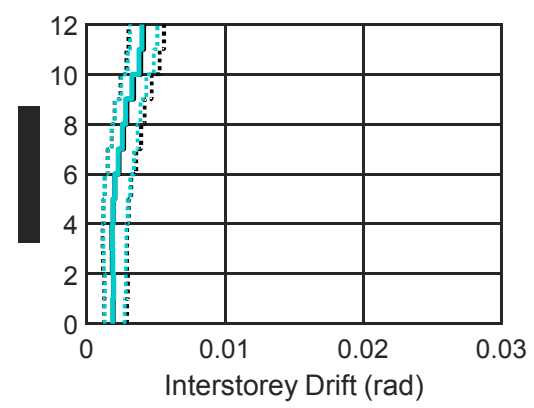

(d)

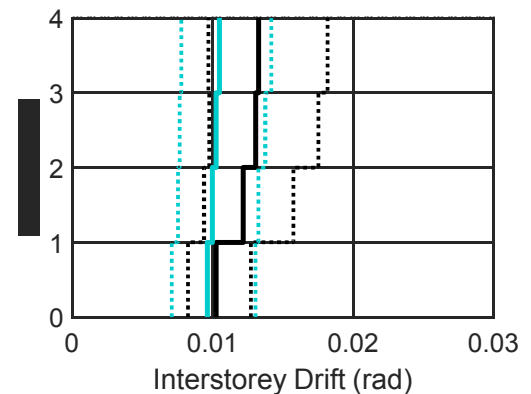

(b)

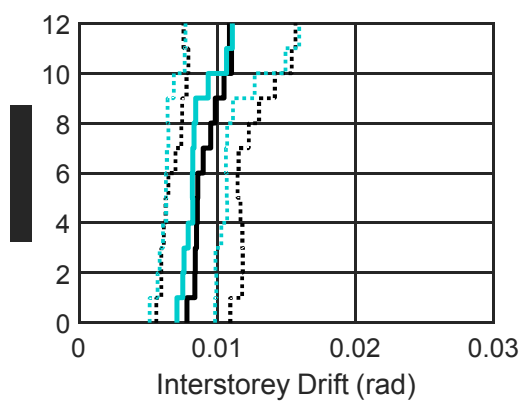

(e)

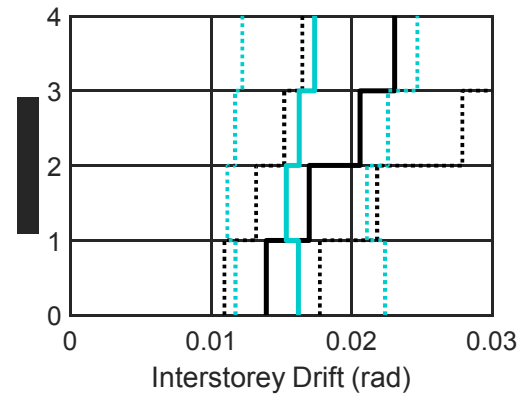

(c)

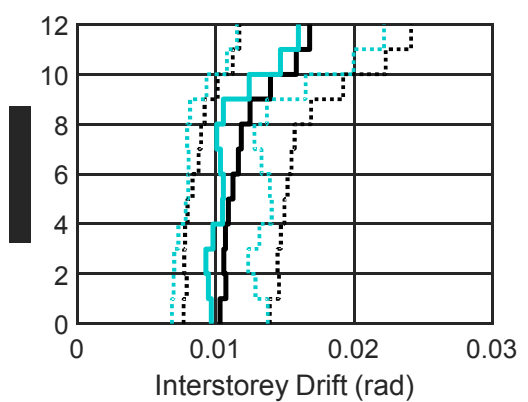

(f)

Figure 8. Comparison of interstorey drifts using 10\% probability of exceedance in 50 year ground motion suite; (a) 4-storey Auckland, (b) 4-storey Christchurch, (c) 4-storey Wellington, (d) 12-storey Auckland, (e) 12-storey Christchurch, and (f) 12-storey Wellington

Figure 9 shows the peak total floor acceleration response of the buildings under the same ground motion record suite. It can be seen that the acceleration response between both connection types are similar regardless of location, with the exception of the 4-storey Wellington buildings where the frame with friction connections had considerably lower accelerations. One reason could be that while the frames with friction connections yield earlier, these do have larger beam sections and are thus elastically stiffer, resulting in shorter higher mode periods that may attract greater spectral accelerations. These two effects may offset each other, leading to a smaller difference in response compared to the drift comparisons. This could also be due to the similar nominal capacity of these frames as discussed previously. 


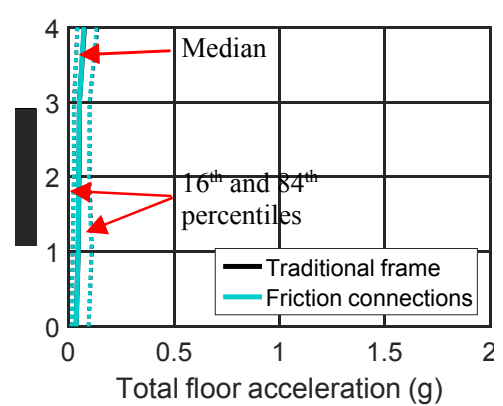

(a)

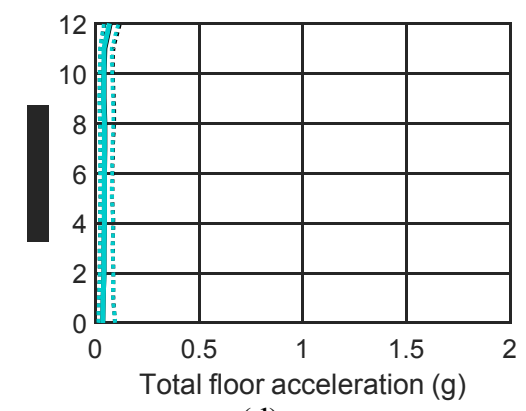

(d)

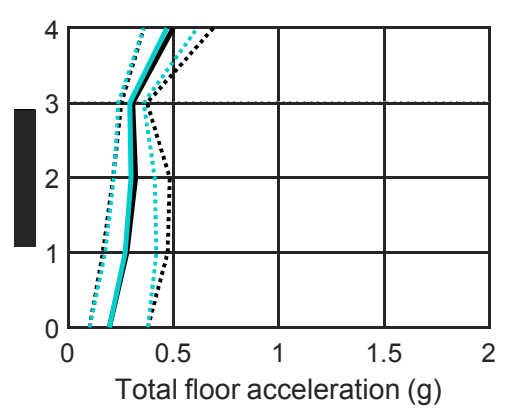

(b)

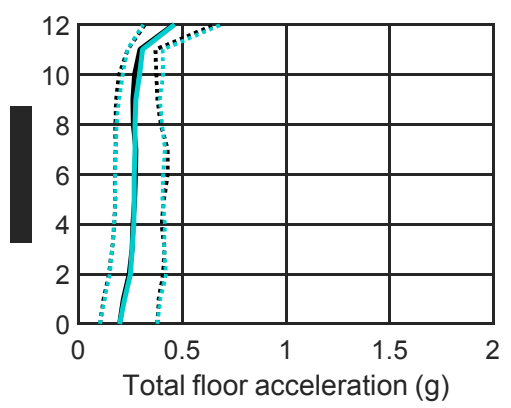

(e)

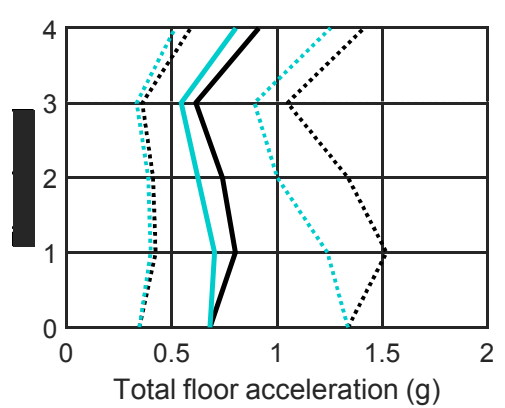

(c)

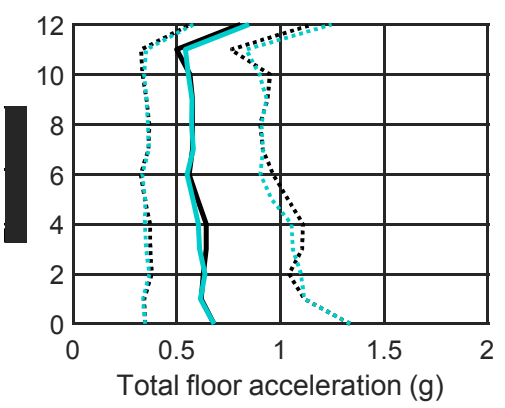

(f)

Figure 9. Comparison of peak total floor accelerations using $10 \%$ probability of exceedance in 50 year ground motion suite; (a) 4-storey Auckland, (b) 4-storey Christchurch, (c) 4-storey Wellington, (d) 12 -storey Auckland, (e) 12-storey Christchurch, and (f) 12-storey Wellington

Based on these observations, frames with friction connections generally incur lower drifts and similar accelerations compared to traditional frames if both are designed to the minimum requirements of the New Zealand standards. Similar observations were made at other shaking intensity levels, and for brevity these results are not shown here.

\subsection{Collapse fragility}

As discussed in the methodology, a peak interstorey drift of 5\% is assumed to correspond to building collapse. None of the ground motions in Auckland caused either building to exceed this drift limit. While some cases in Christchurch do exceed this limit, there are too few to derive a collapse fragility. As such, collapse was not considered for the Auckland or Christchurch regions.

The collapse fragilities for Wellington buildings were derived by firstly determining the number of records which exceeded the 5\% limit for each hazard level to estimate the probability of collapse at the corresponding shaking intensity (Figure 10a). A lognormal distribution was then fitted to data points corresponding to shaking intensities where some, but not all, of the buildings had collapsed (Figure 10b). Visual inspections of Figure 10c show that the estimated fragility is generally within $+/-5 \%$ for seismic intensities where either no collapse had occurred, or where all buildings had collapsed, which is reasonable. Another approach could be to use the cumulative distribution of interstorey drifts to estimate the probability of exceeding the $5 \%$ drift limit at each hazard level before fitting the lognormal distribution; however, in cases where lateral instability occurred, the size of the interstorey drift is extremely large which resulted in a nonsensical distribution of drifts. As such, the approach adopted here was assumed to be more reasonable. 


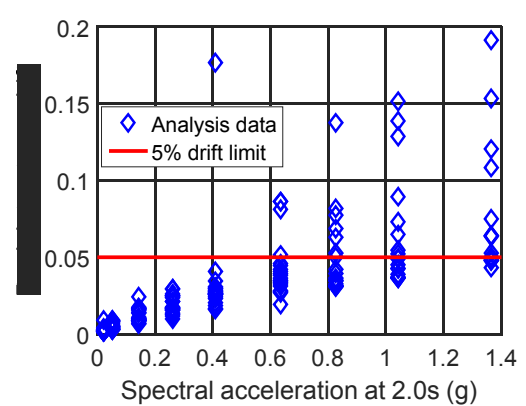

(a)

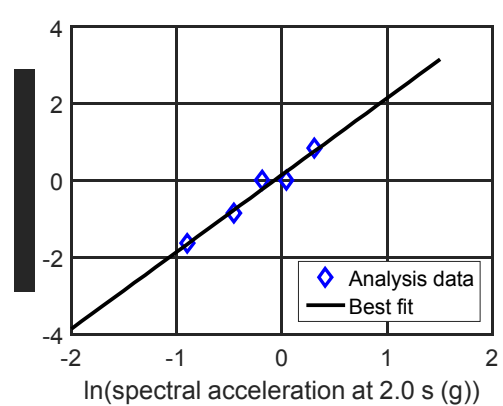

(b)

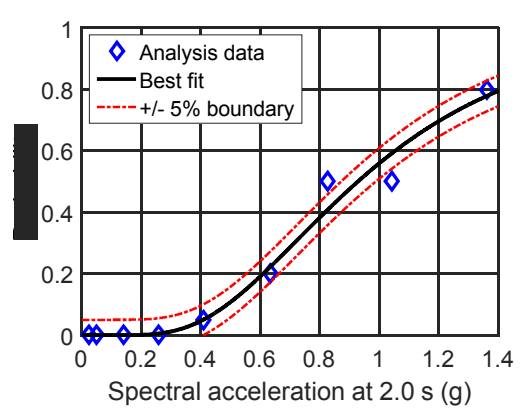

(c)

Figure 10. Computation of collapse fragility; (a) obtaining percentage of analyses exceeding 5\% drift limit, (b) determining best-fit lognormal distribution, and (c) checking lognormal fit

The collapse fragility for the 4-storey and 12-storey Wellington buildings are shown in Figures 11a and 11b, respectively, where it can be seen that the frame with friction connections have a lower probability of collapse based on the definitions adopted in this study.

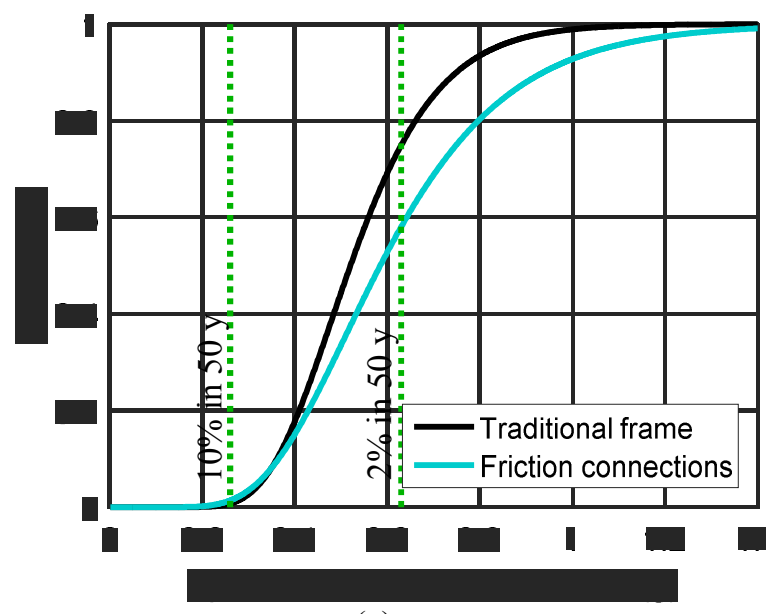

(a)

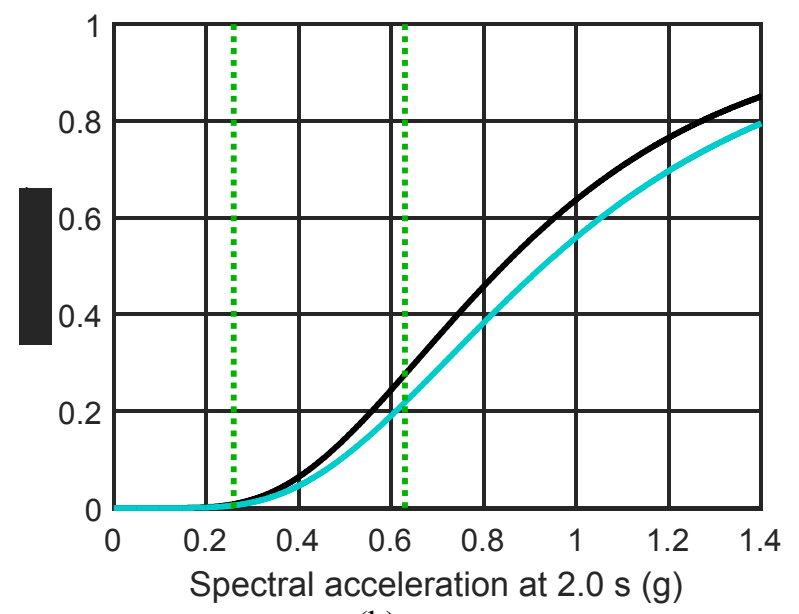

(b)

Figure 11. Comparison of collapse fragility for Wellington; (a) 4-storey building, and (b) 12-storey building

\subsection{Residual drift comparisons}

While residual drifts are not considered in the loss assessments due to lower accuracy from not incorporating strength and stiffness degradation effects, it is still useful to evaluate this response as an indicator of the potential need for demolitions. The distribution of the maximum residual drift recorded across the entire building for each shaking intensity level considering only non-collapse cases are shown in Figure 12. In the Auckland region (Figures 12a and 12d), the frame with the friction connection tends to have larger residual drifts compared to the traditional frame. However, the residual drifts for this case are negligible (less than $0.0015 \mathrm{rad}$ ) and as such are not likely to result in demolitions being required. For the other regions where the seismic hazard is greater, the traditional frame has larger residual drifts compared to the frame with friction connections, which is likely due to the self-centring characteristics of the column and the "pinching" behaviour of the beam-column friction connections in the frame with friction connections. 


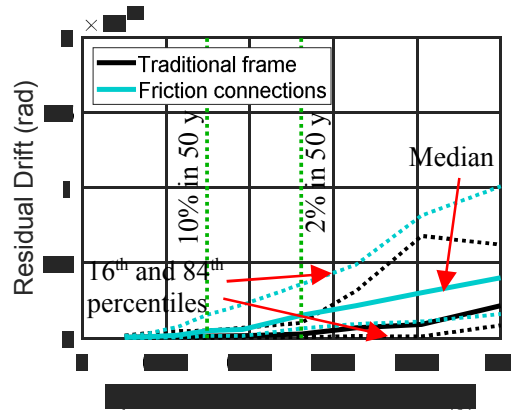

(a)

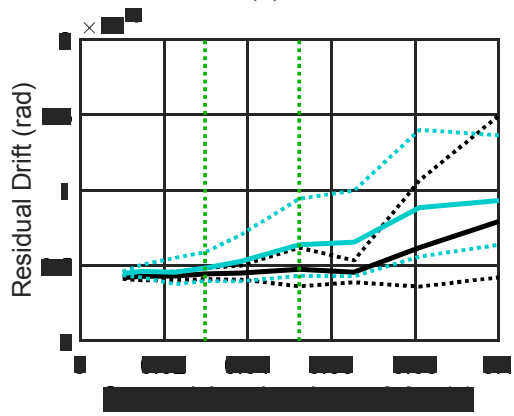

(d)

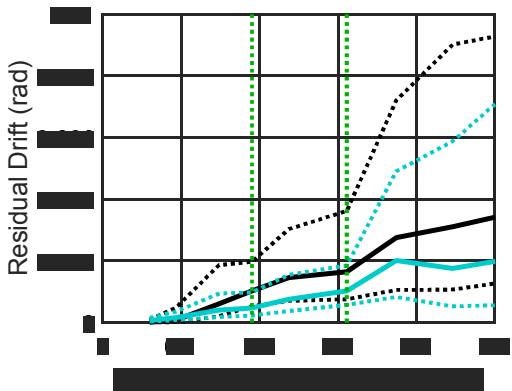

(b)

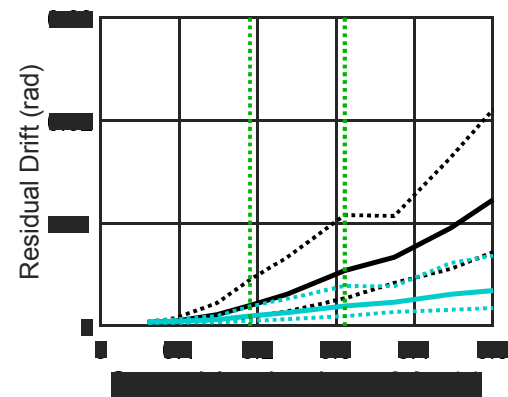

(e)

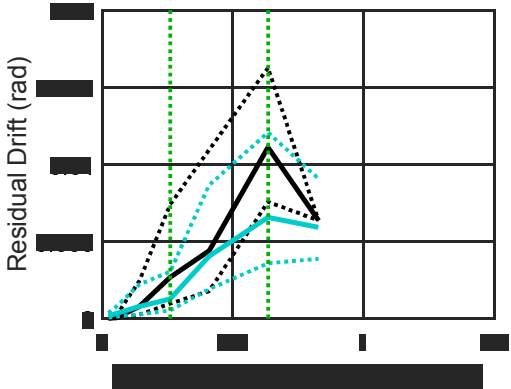

(c)

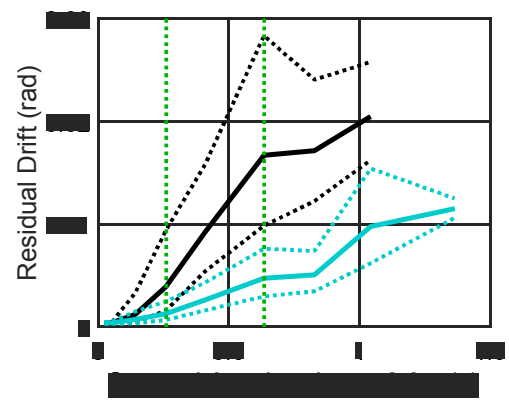

(f)

Figure 12. Comparison of residual drifts with shaking intensity level; (a) 4-storey Auckland, (b) 4-storey Christchurch, (c) 4-storey Wellington, (d) 12-storey Auckland, (e) 12-storey Christchurch, and (f) 12-storey Wellington

FEMA356 (ASCE 2000) recommended a permanent drift value of 1\% for steel moment frames to trigger the "life safety" state where, according to Table C1-2 of the document, the building "may be beyond economical repair". Other studies (Iwata et al. 2005; McCormick et al. 2008) have suggested a residual drift value of $0.5 \%$ instead, both from a financial viewpoint to straighten the building, and from human psychological elements if left unstraightened with occupants possibly incurring headaches and dizziness. Regardless of which drift limit is used, demolition is unlikely to be required in Auckland and for the 4-storey buildings in Christchurch for events smaller than a $2 \%$ in 50 year shaking event. For the 12-storey Christchurch case in Figure 12e, demolition is likely required for the traditional frame, especially after the $10 \%$ in 50 year and $2 \%$ in 50 year hazard level where the $84^{\text {th }}$ percentile residual drift value exceeded $0.5 \%$ and $1 \%$ residual drift, respectively, while the $84^{\text {th }}$ percentile curve for the frame with friction connections only crossed $0.5 \%$ residual drift at $0.4 \mathrm{~g}$. In the case of Wellington, while both building solutions may require demolition, a greater proportion of traditional frames had residual drifts greater than both $0.5 \%$ and $1 \%$ residual drifts. This indicates that if residual drifts are to be used as a measure of the need for demolition, the damage-related cost of traditional frames would likely increase more than that of the frame with friction connections. The consequence of not considering this effect in the loss assessments is discussed later in the paper.

\subsection{COMPARISON OF SEISMIC LOSSES}

\subsection{Loss-IM relationships}

The expected direct-repair costs versus shaking intensity relationships are shown in Figure 13, where the traditional frames incurred larger losses compared to frames with friction connections in all cases. This demonstrates that frames with friction connections would have better performance during an earthquake in terms of repair/replacement cost. One important observation from Figure 13 is that the non-collapse repair cost of the 
buildings rarely exceeded $40 \%$ of their initial construction cost. As such, demolition is not a major factor based on the repair cost-ratio approach.

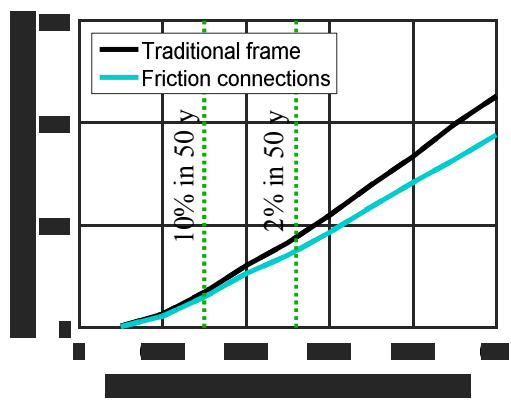

(a)

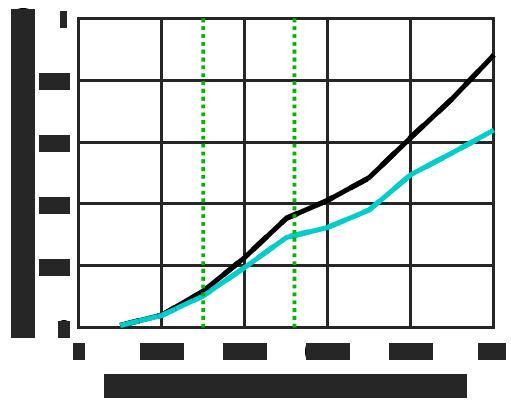

(d)

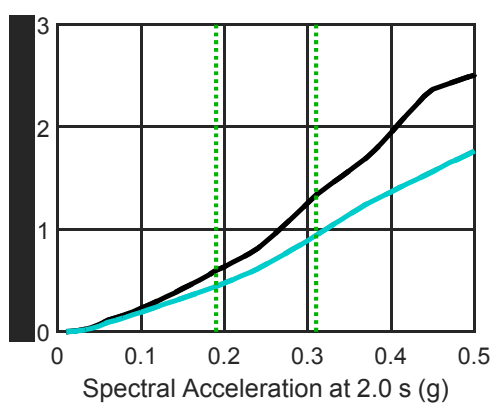

(b)

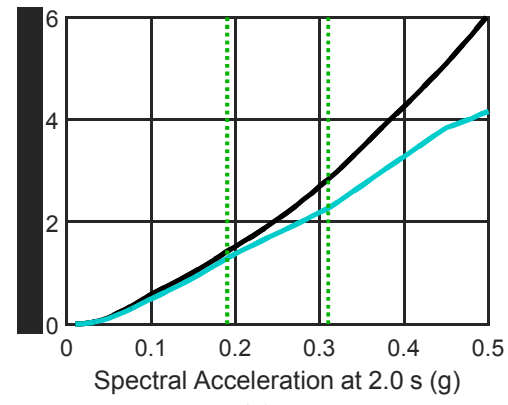

(e)

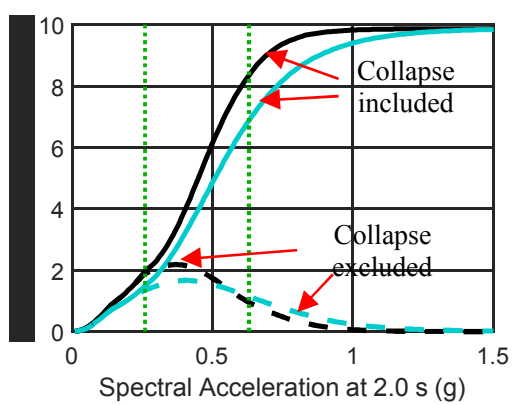

(c)

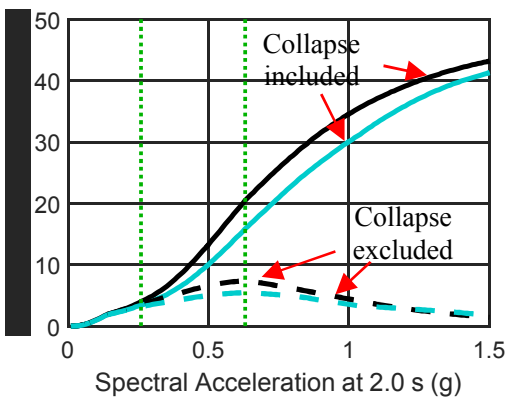

(f)

Figure 13. Expected repair cost versus intensity measure; (a) 4-storey Auckland, (b) 4-storey Christchruch, (c) 4-storey Wellington, (d) 12-storey Auckland, (e) 12-storey Christchurch, and (f) 12-storey Wellington

To investigate if the loss versus shaking intensity relationships are reasonable, the cost breakdown in terms of floor level and component types was examined considering the $10 \%$ in 50 year ground motion shaking intensity. The expected drift-related loss profile with floor level is shown in Figure 14, where the frame with friction connections generally had lower losses on most floors except the ground floor. This is consistent with the drift profiles shown in Figure 8. Similarly, the expected acceleration-related loss profile with floor level in Figure 15 is consistent with the acceleration profiles in Figure 9. Both of these observations indicate that the computed loss trends are reasonable. 


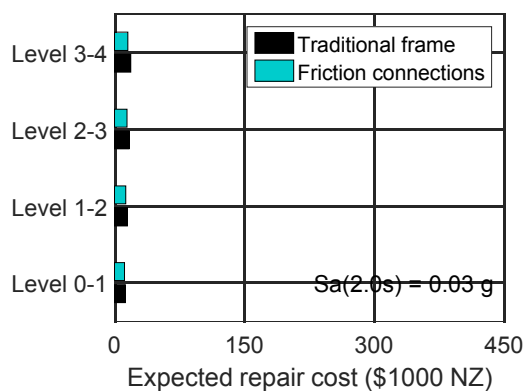

(a)

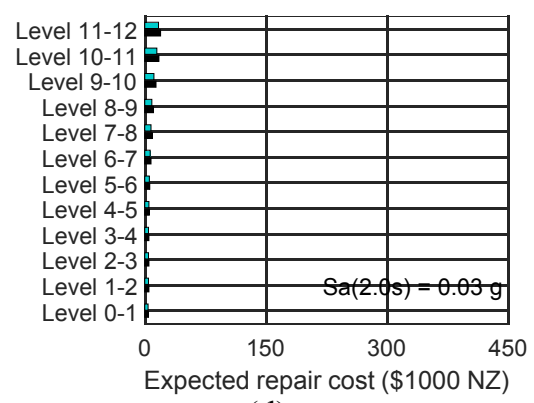

(d)

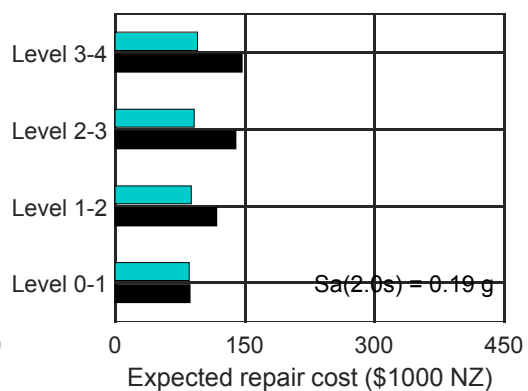

(b)

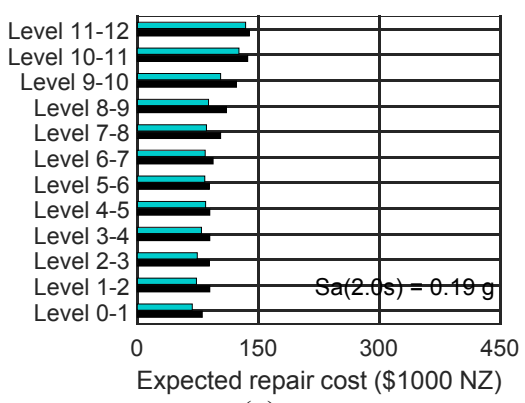

(e)

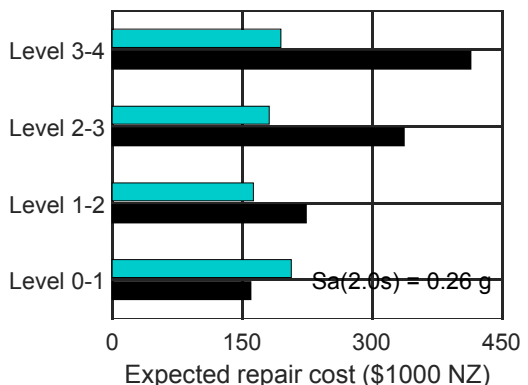

(c)

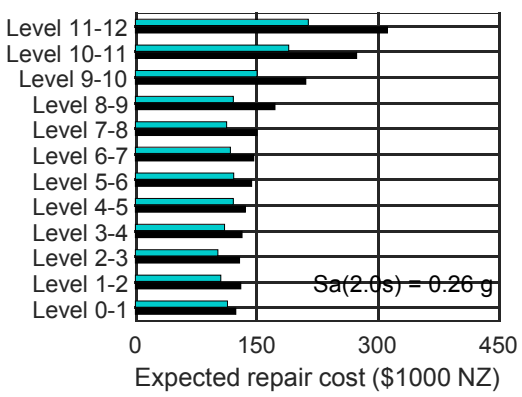

(f)

Figure 14. Breakdown of drift-related expected repair cost by floor level for $10 \%$ in 50 year ground shaking intensity; (a) 4-storey Auckland, (b) 4-storey Christchruch, (c) 4-storey Wellington, (d) 12-storey Auckland,

(e) 12-storey Christchurch, and (f) 12-storey Wellington

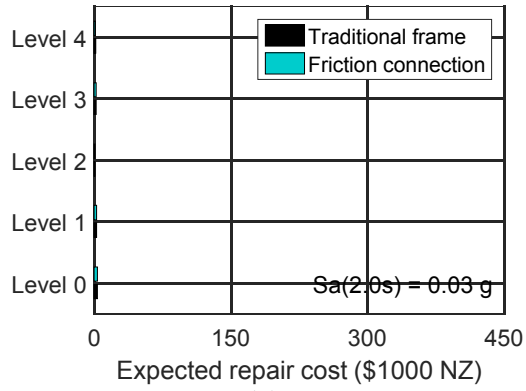

(a)

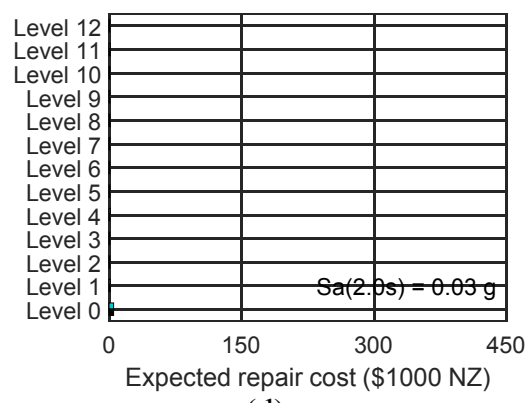

(d)

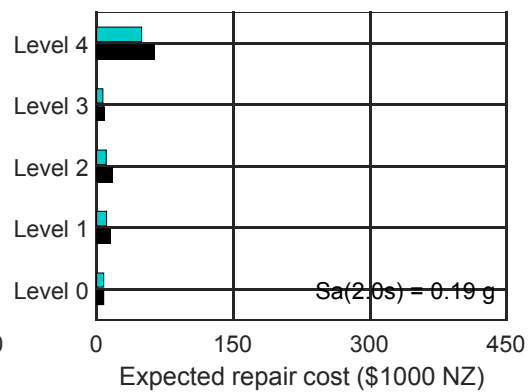

(b)

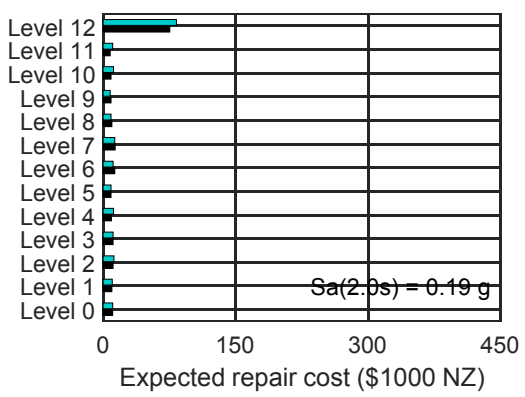

(e)

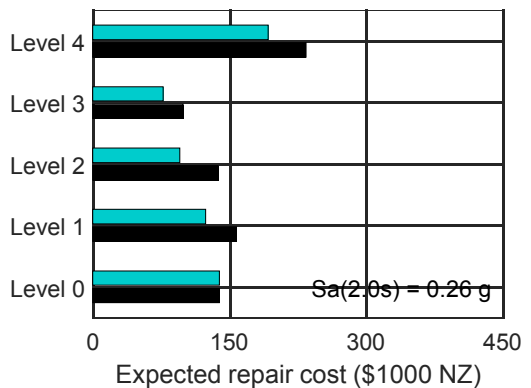

(c)

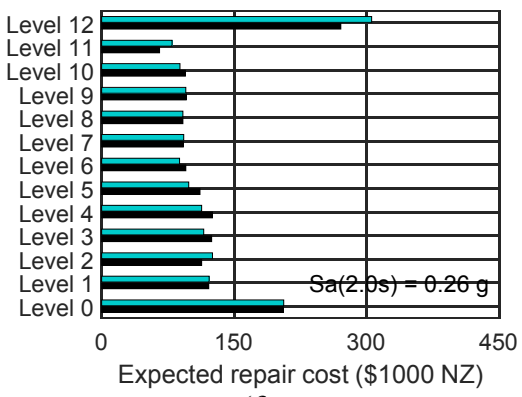

(f)

Figure 15. Breakdown of acceleration-related expected repair cost by floor level for $10 \%$ in 50 year ground shaking intensity; (a) 4-storey Auckland, (b) 4-storey Christchruch, (c) 4-storey Wellington, (d) 12-storey Auckland, (e) 12-storey Christchurch, and (f) 12-storey Wellington

The breakdown of costs by component category is shown in Figure 16, where building components within the frame with friction connections generally have lower losses overall. The main exception to this is the column base connections due to the frame with friction connections generally experiencing greater drifts on the ground floor as observed in Figure 8. For the Wellington buildings, the repair cost of beam connections using the friction connections was lower by $62 \%$ and $37 \%$ compared to the traditional frame for the 4-storey and 12-storey 
buildings, respectively. No other component which has losses greater than $\$ 50,000$ in the traditional frame had a reduction greater than $25 \%$. This demonstrates that the biggest advantage of using friction connections is to reduce repair costs to the connections itself.

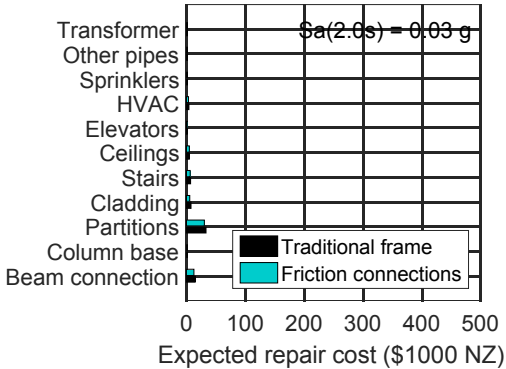

(a)

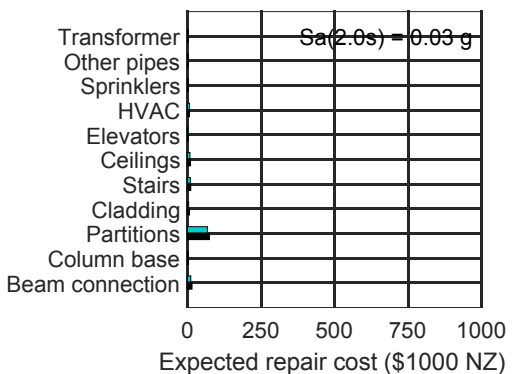

(d)

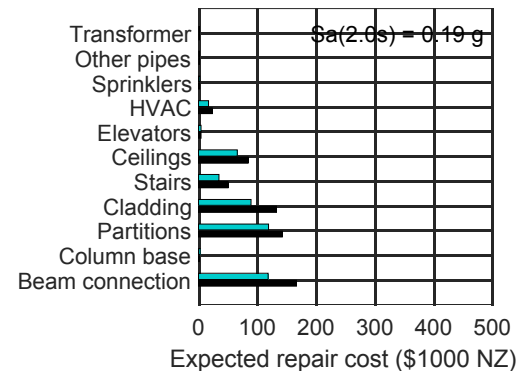

(b)

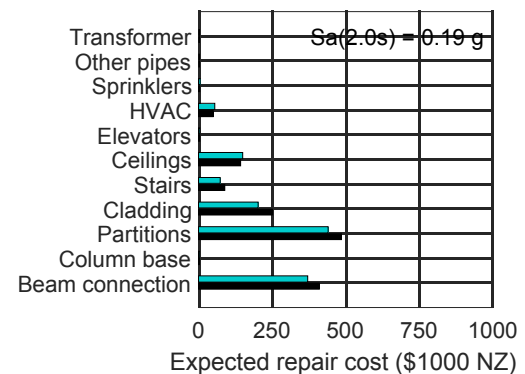

(e)

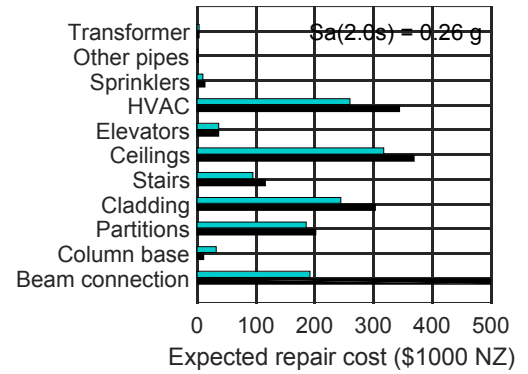

(c)

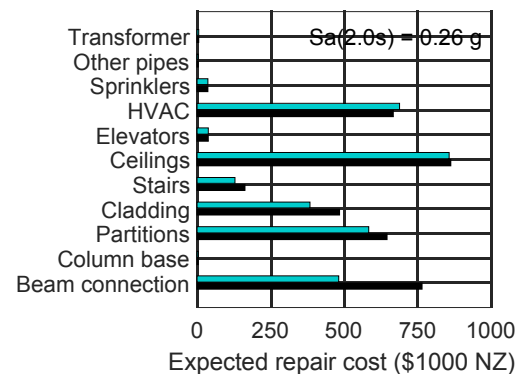

(f)

Figure 16. Breakdown of expected repair cost by component category for $10 \%$ in 50 year ground shaking intensity; (a) 4-storey Auckland, (b) 4-storey Christchruch, (c) 4-storey Wellington, (d) 12-storey Auckland, (e) 12-storey Christchurch, and (f) 12-storey Wellington

\subsection{Expected annual loss}

The computed expected annual loss for each building, expressed as both absolute cost and as a percentage of fullreplacement cost, and its dispersion ( $\beta$ ) are shown in Table 5. One observation here is that $E A L$ is larger for the taller buildings in terms of absolute cost, but is smaller in terms of percentage of full-replacement $\operatorname{cost}(F R C)$. Similar observations have also been made in past seismic loss studies (Calvi et al. 2014; Ramirez et al. 2012; Sullivan 2016). One reason is that the response of the 12-storey building is generally lower than that of the 4storey building on most floors as shown in Figures 8 and 9, which is possibly due to a larger drift modification factor, $k_{d m}$, being considered for the taller building following NZS1170.5 (Standards New Zealand 2004). Furthermore, the cost of repair of individual beam components may not have increased significantly despite large sections being used in the 12-storey building, such as the cost of visual inspections.

Table 5. Annual loss of each building

\begin{tabular}{|c|c|c|c|c|c|c|c|c|c|c|c|c|}
\hline \multirow{3}{*}{ Location } & \multicolumn{6}{|c|}{ 4-storey building } & \multicolumn{6}{|c|}{ 12-storey building } \\
\hline & \multicolumn{3}{|c|}{ Traditoinal frame } & \multicolumn{3}{|c|}{ Friction connections } & \multicolumn{3}{|c|}{ Traditoinal frame } & \multicolumn{3}{|c|}{ Friction connections } \\
\hline & $\begin{array}{c}\text { EAL } \\
(\mathrm{NZD})\end{array}$ & $\begin{array}{l}\text { EAL (\% } \\
\text { of FRC) }\end{array}$ & $\beta$ & $\begin{array}{c}\text { EAL } \\
\text { (NZD) }\end{array}$ & $\begin{array}{l}\text { EAL ( } \% \\
\text { of FRC) }\end{array}$ & $\beta$ & $\begin{array}{c}\text { EAL } \\
(\mathrm{NZD})\end{array}$ & $\begin{array}{l}\text { EAL }(\% \\
\text { of FRC) }\end{array}$ & $\beta$ & $\begin{array}{c}\text { EAL } \\
\text { (NZD) }\end{array}$ & $\begin{array}{l}\text { EAL (\% } \\
\text { of FRC) }\end{array}$ & $\beta$ \\
\hline & 706 & & 3.4 & & & 3.4 & 1,270 & & 3.5 & & & 3.4 \\
\hline Chris & 11,400 & 0.107 & 3.6 & 9,030 & & 3.5 & 25,800 & 0.050 & 3.7 & 22,100 & 0. & 3.6 \\
\hline Wellington & 18,100 & 0.184 & 3.9 & 15,000 & 0.151 & 3.9 & 41,000 & 0.087 & 4.1 & 35,000 & 0.074 & 4.1 \\
\hline
\end{tabular}

It is important to acknowledge that significant variation in annual losses exists as shown by the dispersions in

Table 5. As such, the focus on EAL may hide the large uncertainty in the loss assessment process, and investigations regarding the statistical significance of annual losses should be undertaken in future work. Despite 
this, $E A L$ is still a useful measure of relative performance, and identifying the shaking intensities which contribute the most to $E A L$ can provide some insight regarding efficient strategies to limit losses in future events. Consider Figure 17 which shows the cumulative contribution of losses at various levels of shaking intensity to $E A L$, where it can be seen that $40-80 \%$ of contributions to $E A L$ arises from seismic intensities smaller than a $10 \%$ in 50 year probability of exceedance event. This shows that an effective way to reduce $E A L$ could be to improve the performance of the buildings for events below or equivalent to this shaking intensity, which based on Figure 13, was not necessarily achieved by the frame with friction connections.

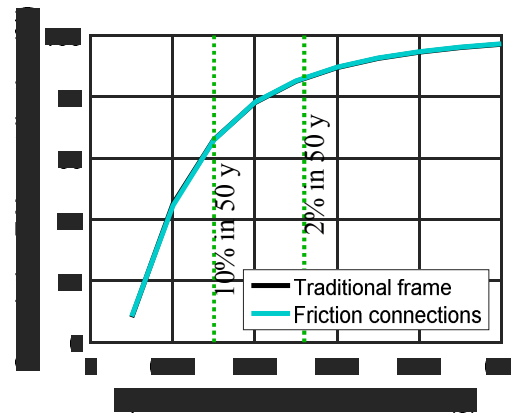

(a)

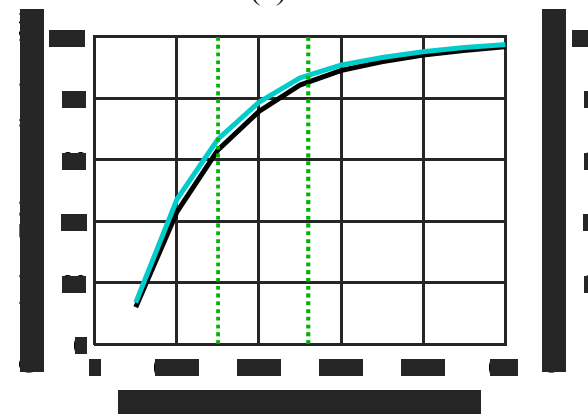

(d)

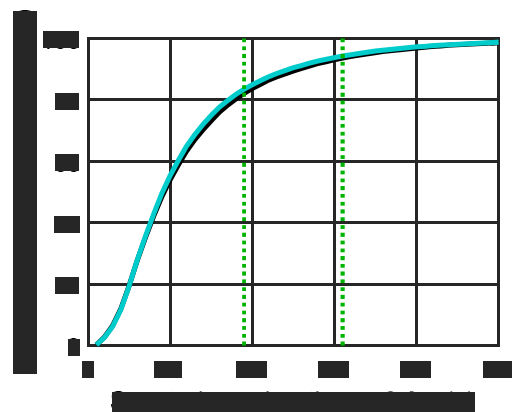

(b)

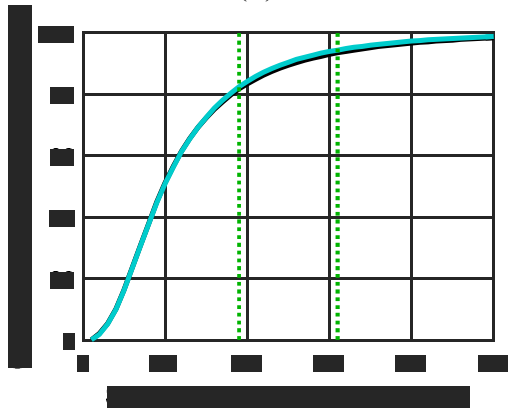

(e)

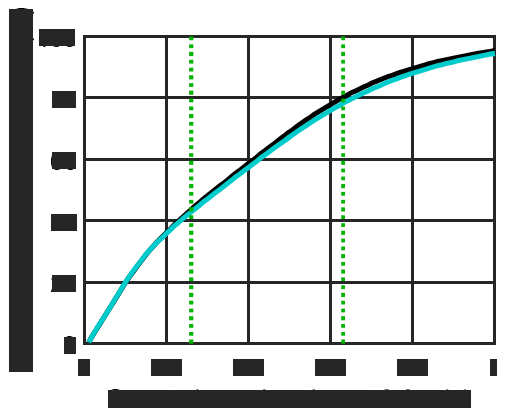

(c)

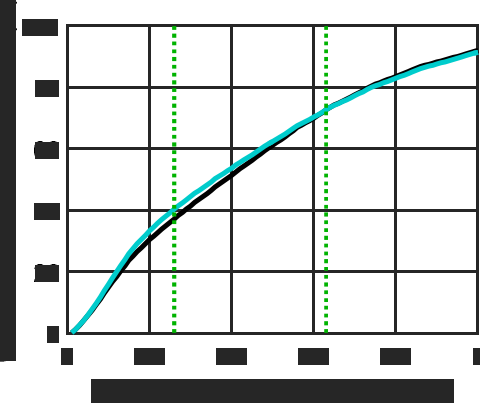

(f)

Figure 17. Intensity measure contribution to expected annual loss; (a) 4-storey Auckland, (b) 4-storey Christchurch, (c) 4-storey Wellington, (d) 12-storey Auckland, (e) 12-storey Christchurch, and (f) 12-storey Wellington

\subsection{Net-present-cost assessment}

The net-present-cost assessment provides an indication of the expected cumulative losses with time, in addition to differences in initial construction cost, converted back to present value. This can be useful to identify if implementation of friction connections is likely to pay off within a given duration of the building being in service. Net-present-cost curve comparisons using the difference in building values from Table 4 and the expected annual loss from Table 5 are shown in Figure 18. Neither of the Auckland cases (Figures 18a and 18d) showed much economic benefit from using friction connections. This is to be expected as the seismic losses in Auckland are small due to its low seismicity observed from both PSHA and NZS1170.5 (Standards New Zealand 2004).

For the remaining four cases, frames with friction connections tend to have a shorter time to return on investment for buildings in Wellington compared to those in Christchurch (comparing Figures 18b to 18c and Figures 18e to 18f) and/or for shorter buildings (comparing Figures 18b to 18e and Figures 18c and 18f). The former is due to the seismic hazard being larger in Wellington compared to Christchurch as observed in Figure 6 previously, which results in larger damage and losses occurring at the same ground shaking probability of exceedance in 50 years as observed in Figure 13, and hence greater $E A L$ as observed in Table 5. The latter is due to the losses not increasing proportionately to the increase in construction costs as discussed previously. 
Observing Figure 18 in more detail, it can be seen that the 4-storey frames with friction connections in both Christchurch and Wellington had lower NPC at the end of 50 years compared to the traditional frames, with the intercepts occurring around 6 to 7 years and around 3 years for Christchurch and Wellington, respectively. This demonstrates that there could be significant financial incentive for using friction connections for low-rise buildings. The 12-storey frame with friction connections in Wellington has an intercept around 16 to 27 years, which highlights that while the time to return on investment is not as short as for the low-rise buildings, this building solution is still competitive considering direct-repair costs only. The 12-storey Christchurch frame with friction connections however is less competitive, and reasons for this are explored later.

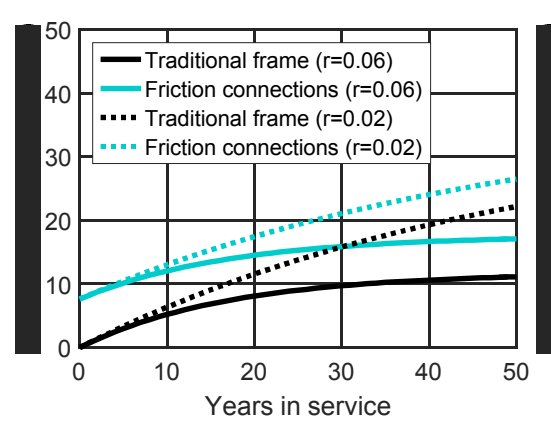

(a)

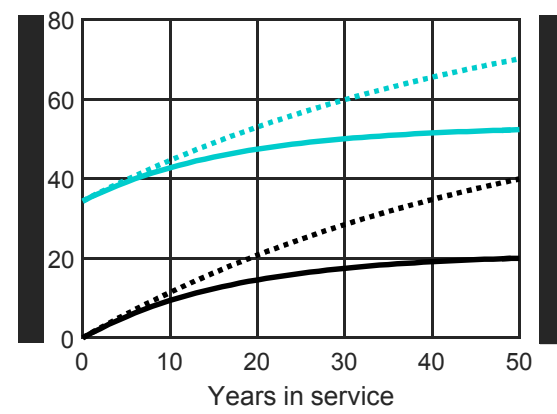

(d)

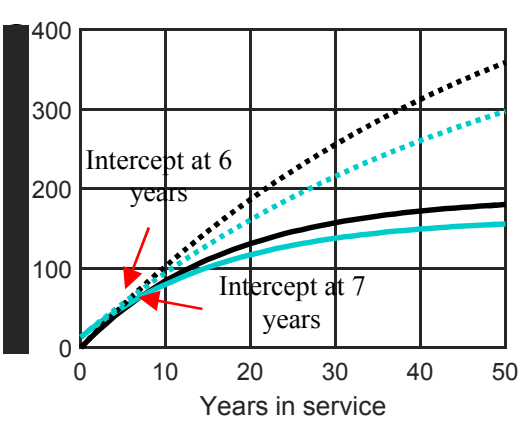

(b)

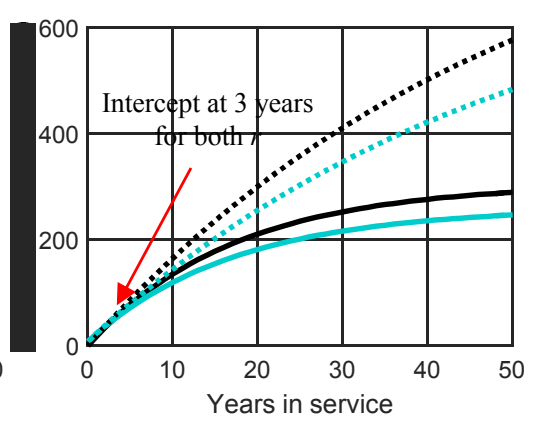

(c)

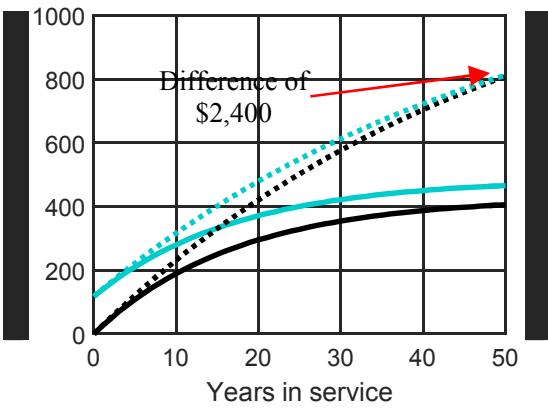

(e)

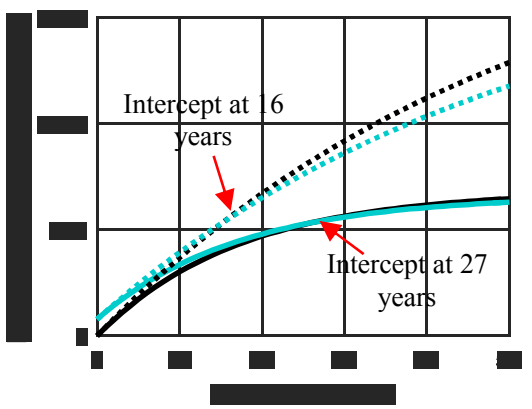

(f)

Figure 18. Net present cost assessment; (a) 4-storey Auckland, (b) 4-storey Christchruch, (c) 4-storey Wellington, (d) 12-storey Auckland, (e) 12-storey Christchurch, and (f) 12-storey Wellington

\subsection{DISCUSSION}

\subsection{Importance of seismic hazard}

Generally, frames with friction connections are more economically beneficial in Wellington and Christchurch, except for the 12-storey building case in Christchurch. One of the reasons why the 12-storey frame with friction connections was not economically beneficial in Christchurch could be due to the low seismic hazard obtained from PSHA compared to that used in design following NZS1170.5 (Standards New Zealand 2004). The inconsistency not only affects the seismic losses, but possibly also the building value as the beam sizes would have likely been smaller had the seismic hazard obtained from PSHA been used in design instead. To investigate the effect of seismic hazard, the $E A L$ and $N P C$ were recalculated using the code seismic hazard instead. The code seismic hazard was approximated by fitting a hyperbolic curve fit, in line with recommendations of Bradley et al. (2007), to the design horizontal spectra values adjusted for the return period factor, and is shown in Figure 19a.

It can be seen from Figure 19b that NPC analyses suggests that the 12-storey frame with friction connections is likely to be more economically beneficial than the traditional frame at 13 and 22 years for $r=2 \%$ and $6 \%$, 
respectively. This is in sharp contrast to observations from Figure 18e where the time to return of investment exceeds 50 years for both values of $r$. This demonstrates the significant influence of the seismic hazard in the costbenefit assessment.

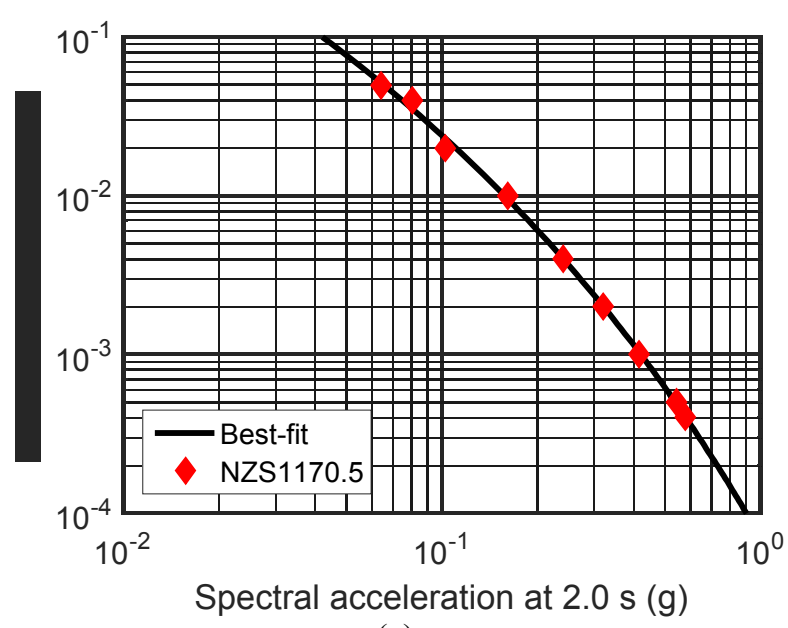

(a)

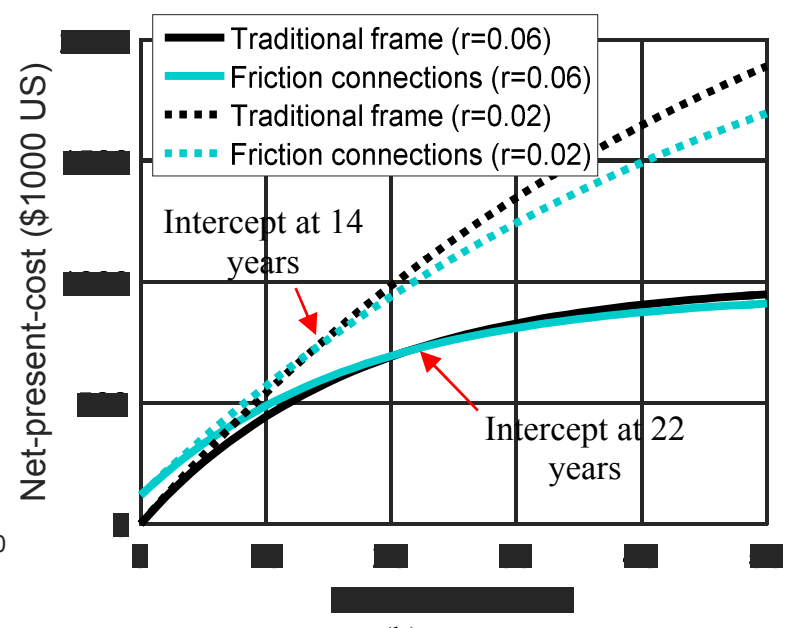

(b)

Figure 19. Effect of seismic hazard on net-present-cost analysis; (a) approximated code seismic hazard for Christchurch subsoil class D Sa(2.0s), and (b) net-present-cost analysis of 12-storey Christchurch building

\subsection{Impact of residual drifts}

As discussed previously, the lack of a strength and stiffness degradation model for friction connections mean that the estimation of residual drifts may not be accurate, and as such this was not considered in the loss analyses. This section investigates the potential impact of excluding residual drifts in the assessment by revaluating the losses for the 12-storey buildings located in Christchurch considering the hazard curve from Figure $6 \mathbf{b}$.

Assuming that the residual drift output examined in Section 4.3 are reasonable, and that 1\% residual drift (obtained from FEMA356 (ASCE 2000)) triggers the need for demolitions, the probability of requiring demolition for the 12-storey buildings for Christchurch is as shown in Figure 20a. Here, the probability of requiring demolition is significantly larger for the traditional frame compared to the frame with friction connections.

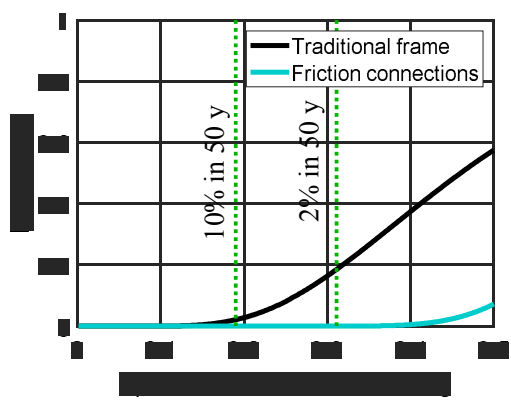

(a)

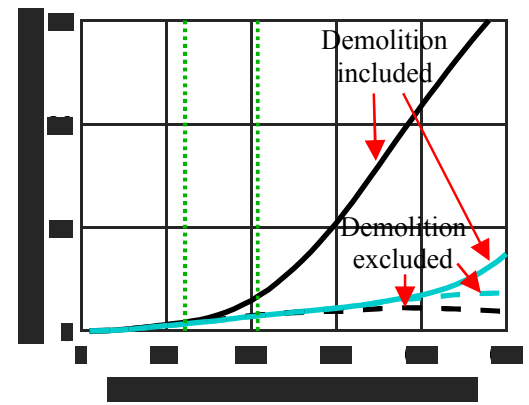

(b)

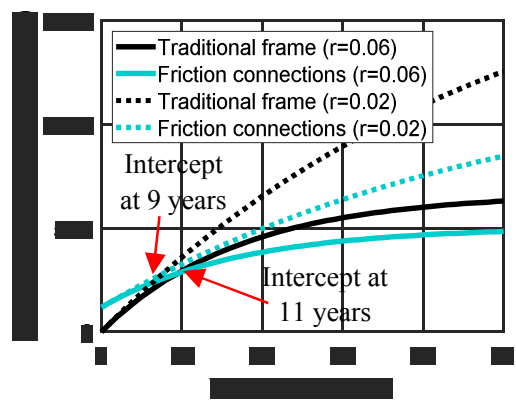

(c)

Figure 20. Potential effect of considering residual drifts in the loss assessment; (a) demolition fragility curve, (b) expected loss-im results, and (c) net-present-cost assessment

The expected repair cost versus shaking intensity relationships were recomputed using the demolition fragility curve from Figure 20a, the result of which is as shown in Figure 20b. The expected repair cost of the traditional frame increased significantly compared to the previously calculated expected repair cost in Figure 13e, while the repair cost of the frame with friction connections remained relatively similar. The expected annual cost calculated for the traditional frame and the frame with friction connections were $\$ 40,000$ and $\$ 23,200$, respectively. The 
difference between these values $(\$ 16,800)$ is noticeably greater than that obtained excluding residual drift considerations $(\$ 3,700)$. This resulted in the time to return on investment ranging from 9 to 11 years as shown in Figure 20c, compared to over 50 years previously. This shows that the consideration of residual drifts is likely to make friction connections an even more cost-effective solution.

It should be noted that if $0.5 \%$ residual drift is considered instead of $1.0 \%$ residual drift, the expected annual cost of the traditional frame and the frame with friction connections becomes $\$ 62,100$ and $\$ 26,300$, respectively. The resulting range of the time to return on investment for the frame with friction connections reduces to 4 to 5 years, which is about half the time if $1.0 \%$ residual drifts was considered. This highlights that the selection of residual drifts may be significant in influencing decision-making; though in either case the frame with the friction connections is still the more cost-effective solution.

\subsection{Impact of design and modelling decisions}

There are several key design and modelling decisions which could have affected the findings obtained in this study. One such decision is to compare the performance of the buildings designed to obtain the lightest steel frame possible which met minimum allowable standards. It is possible that a design which is heavier and has higher initial construction cost could have a lower $N P C$ overall. For example, if Grade 300 steel was adopted for the frame with friction connections instead, larger beams would be used which would stiffen the frame, resulting in lower drifts and probability of collapse but potentially increasing accelerations. Methods to also stiffen the frame, such as choosing between increasing the beam or column size, could also have an effect. Nonetheless, the comparisons made in this paper are still useful to provide an indication on the relative performance of these buildings with time.

Another potentially significant modelling decision is the exclusion of strength and stiffness deterioration effects in the structural model, and instead imposing a 5\% drift limit to approximate collapse effects and ignoring residual drifts altogether in the loss analyses as discussed previously. As the 5\% limit was based on code recommendations, it is likely to be on the conservative side for both the traditional frame and the frame with friction connections, which would result in a decrease in expected annual loss and net-present-costs for both connection variants if strength and stiffness deterioration is considered. However, the frame with the friction connections should have a greater percentage decrease as it is able to withstand rotations of up to $120 \mathrm{mrad}$ before fracture occurs (Clifton 2002), which is much higher than that which steel beam elements are typically able to achieve. It is not immediately clear how the difference in expected annual loss between both connection variants and the time to return on investment for the frame with friction connections would change, but despite this uncertainty the frame with friction connections would most likely remain a cost-effective solution for most steel moment-resisting frames in the Christchurch and Wellington region. Nonetheless, experimental work is required to better understand the strength and stiffness deterioration properties of friction connections so that these could be modelled in the future. Results from such work would also be beneficial to develop higher quality fragility functions for friction connections.

\subsection{Other considerations}

While this study has focused on comparing the performance of steel moment resisting frames with friction connections against that of frames with more traditional connections considering direct-repair costs and net- 
present-cost analyses, it is only one of many performance measures. Injuries and downtime are other examples of losses within the PEER framework which were not considered in this study. As the moment resisting frames with friction connections generally had lower drifts but similar accelerations compared to their traditional counterparts, it is likely that corresponding injuries would also be reduced. Furthermore, a key attraction of friction connections is its ease of reparability which would decrease downtime. The ease of reparability would also likely reduce costs of repairs at height, especially if repair work consists of mainly re-tightening or replacing bolts rather than replacing the beam itself. Consideration of these factors, which are outside the scope of this study, would likely make frames with friction connections a more attractive option compared to considering direct-repair cost on its own.

\subsection{CONCLUSIONS}

This study investigated the cost effectiveness of using friction beam-column joint connections over more traditional variants (e.g. extended bolted-end-plate connections) using seismic loss estimation. In general, it was found that:

1) Frames with friction connections tended to require larger beam section sizes compared to those with traditional connections to satisfy connection overstrength requirements following capacity design principles.

2) Frames with friction connections generally exhibited smaller peak interstorey drifts, similar peak total floor accelerations, and had a lower probability of collapse compared to frames with more traditional connection variants.

3) Frames with friction connections incur lower damage direct-repair costs for most components and floor levels compared to frames with more traditional connection variants. The building component with the largest reduction in repair/replacement cost was beam connections.

4) Net-present-cost analyses indicated that the time to return on investment is 7 years or less than for the 4storey buildings in Christchurch and Wellington. For the 12-storey Wellington scenario, the time to return on investment is around 27 years or less depending on the discount rate adopted. The duration is greater than 50 years for the Auckland scenario due to its low seismicity, and for the 12-storey Christchurch case when residual drifts are not considered in the loss assessment.

\subsection{ACKNOWLEDGEMENTS}

This project was supported by QuakeCoRE, a New Zealand Tertiary Education Commission-funded Centre. This is QuakeCoRE publication number 0256.

The authors would also like to acknowledge Brendon Bradley and Karim Tarbali for their guidance on performing probabilistic seismic hazard analyses and ground motion selection; Shahab Ramhormozian and Robin Xie for their advice regarding design, modelling, and repair of friction connections; and Stuart Oliver for recommendations regarding typical building dimensions.

Information on ground motion records and building components (quantity, fragility, and consequence functions) are available at the following link: 
https://wiki.canterbury.ac.nz/display/QuakeCore/Project+17137+-

+ Usage + of + Seismic + Loss + Assessment + to + Motivate + High + Performance + Building + Solutions.

\section{REFERENCES}

Applied Technology Council (2012a) Seismic Performance Assessment of buildings Volume 1 - Methodology. California, US

Applied Technology Council (2012b) Seismic Performance Assessment of buildings Volume 2 - Implementation Guide. California, US

ASCE (2000) Prestandard and Commentary for the Seismic Rehabilitation of Buildings. Federal Emergency Management Agency, Washington, D.C.

ASCE (2013) Seismic evaluation and retrofit of existing buildings (ASCE/SEI 41-13). American Society of Civil Engineers, Reston, VA.

Aslani H, Miranda E (2005) Probabilistic Earthquake Loss Estimation and Loss Disaggregation in Buildings. Department of Civil and Environmental Engineering, Stanford University,

Baker JW, Jayaram N (2008) Correlation of Spectral Acceleration values from NGA ground motion models. Earthquake Spectra 24:299-317

Borzouie J, MacRae GA, Chase GJ, Rodgers GW, Clifton GC (2015) Experimental studies on cyclic performance of column base strong axis-aligned asymmetric friction connections Journal of Structural Engineering 142:04015078

Bradley BA (2010) A Generalized Conditional Intensity Measure Approach and Holistic Ground Motion Selection Earthquake Engineering and Structural Dynamics 39:1324-1342 doi:10.1002/eqe.995

Bradley BA (2011a) Correlation of significant duration with amplitude and cumulative intensity measures and its use in ground motion selection Journal of Earthquake Engineering 15:809-832

Bradley BA (2011b) SLAT:Seismic Loss Assessment Tool (Version 1.16). Department of Civil and Natural Resources Engineering, University of Canterbury,

Bradley BA (2012a) A Ground Motion Selection Algorithm Based on the Generalized Conditional Intensity Measure Approach Soil Dynamics and Earthquake Engineering 40:48-61 doi:10.1016/j.soildyn.2012.04.007

Bradley BA (2012b) The Seismic Demand Hazard and Importance of the Conditioning Intensity Measure Earthquake Engineering and Structural Dynamics 41:1417-1437 doi:10.1002/eqe.2221

Bradley BA (2013) A New Zealand-Specific Pseudospectral Acceleration Ground-Motion Prediction Equation for Active Shallow Crustal Earthquakes Based on Foreign Models Bulletin of the Seismological Society of America 103:1801-1822 doi:10.1785/0120120021

Bradley BA, Dhakal RP, Cubrinovski M, MacRae GA, Lee DS (2009a) Seismic Loss Estimation for Efficient Decision Making Bulletin of the New Zealand Society of Earthquake Engineering 42:96-110

Bradley BA, Dhakal RP, Cubrinovski M, Mander JB, MacRae GA (2007) Improved seismic hazard model with application to probabilsitic seismic demand analysis Earthquake Engineering and Structural Dynamics $36: 2211-2225$

Bradley BA, Lee DS, Broughton R, Price C (2009b) Efficient Evaluation of Performance-based Earthquake Engineering Equations Structural Safety 31:65-74 doi:10.1016/j.strusafe.2008.03.003

Bruneau M, MacRae GA (2017) Reconstructing Christchurch: a seismic shift in building structural systems. The Quake Centre, University of Canterbury

Calvi GM, Sullivan TJ, Welch RP A seismic performance classification framework to provide increased seismic resilience. In: 2nd European conference on earthquake engineering and seismology, Istanbul, 25 August - 29 August 20142014.

Campbell KW, Bozorgnia Y (2010) A Ground Motion Prediction Equation for the Horizontal Component of Cumulative Absolute Velocity (CAV) Based on the PEER-NGA Strong Motion Database Earthquake Spectra 26:635-650 doi:10.1193/1.3457158 
Carr AJ (2004) Ruaumoko 2D - Inelastic dynamic analysis program. Department of Civil and Natural Resources Engineering, University of Canterbury, Christchurch

Caughey TK (1960) Calssical Normal Modes in Damped Linear Systems Journal of Applied Mechanics 27:269271

CEN (Comite' Europe'en de Normalisation) (2009) Eurocde 3: design of steel structures - Part 1-8: Design of joints. Comite' Europe'en de Normalisation, Brussels, Belgium

Clifton CG (2002) The Sliding Hinge Joint Design and Construction Bulletin 68:Heavy Engineering Research Association, Auckland, New Zealand

Clifton GC (2005) Semi-rigid joints for moment-resisting steel framed seismic-resisting systems. The University of Auckland, Auckland, New Zealand

Cooper M, Carter R, Fenwick R (2012a) Canterbury Earthquake Royal Commission Final Report Volume 1 Summary and recommendations in volumes 1-3, seismicity, soils and the design design of buildings. Canterbury Earthquake Royal Commission, Wellington

Cooper M, Carter R, Fenwick R (2012b) Volume 2 - The Performance of Christchurch CBD Buildings. Canterbury Earthquake Royal Commission,

Cowie K (2010) Design example of moment resisting seismic frames with reduced beam sections. Steel Construction of New Zealand

Deierlein GG, Krawinkler H, Cornell CA A Framework for Performance-based Earthquake Engineering. In: 2003 Pacific Conference on Earthquake Engineering, Christchurch, New Zealand, 2003.

Elwood KJ, Marquis F, Kim JH Post-earthquake assessment and repairability of RC buildings: lessons from Canterbury and emerging challenges. In: Tenth Pacific Conference on Earthquake Engineering, Sydney, Australia, 2015.

Field EH, Jordan TH, Cornell CA (2003) OpenSHA: A Developing Community-Modeling Environment for Seismic Hazard Analysis Seismological Research Letters 74:406-419

Gates C (2015) 1240 central Christchurch buildings demolished video. Fairfax New Zealand Limited, The Press

Goda K, Atkinson GM (2009) Probabilistic characterization of spatially correlated response spectra for earthquakes in Japan Bulletin of Seismological Societyof America 99:3003-3020

Golondrino JC, Xie R, MacRae GA, Chase GJ, Rodgers GW, Clifton GC Low damage brace using a symmetrical friction connection detail. In: 2015 New Zealand Socierty for Earthquake Engineering Conference, Rotorua, 2015.

Haselton CB, Baker JW (2017) Seismic performance prediction program, 2.6 edn., Haselton Baker Risk Group, Chico

Iwata Y, Sugimoto H, Kuwamura H (2005) Reparability Limit of Steel Structural Buildings: Study on performance-based design of steel structural buildings Part2. Journal of Structural and Construction Engineering:165-172. (in Japanese)

Kempton JJ, Stewart JP (2006) Prediction equations for significant duration of earthquake ground motions considering site and near-source effects Earthquake Spectra 22:985-1013

Khoo H-H, Clifton C, MacRae G, Zhou H, Ramhormozian S (2015) Proposed design models for the asymmetric friction connection Earthquake Engineering \& Structural Dynamics 44:1309-1324 doi:10.1002/eqe.2520

Khoo H-H, Clifton GC, Butterworth J, MacRae GA, Gledhill S, Sidwell G (2012) Development of the selfcentering sliding hinge joint with friction ring springs Journal of Constructional Steel Research 78:201211

Khoo HH (2013) Development of the low damage self-centering sliding hinge joint. University of Auckland, Auckland, New Zealand

Kim KD, Engelhardt MD (2002) Monotonic and cyclic loading models for panel zones in steel moment frames Journal of Constructional Steel Research 58:605-635

Leung HK, Clifton GC, Khoo HH, MacRae GA Experimental studies of eccentrically braced frame with rotational bolted active links. In: 8th International Conference on Behavior of Steel Structures in Seismic Areas, Shanghai, China, 2015. 
MacRae G, Clifton C Research on sesimic performance of steel structures. In: Steel Innovations 2015, Auckland, New Zealand, 2015.

MacRae GA, Clifton CG, Mackinven H, Mago n, Butterworth J, Pampanin S (2010) The sliding hinge joint moment connection Bulletin of the New Zealand Society for Earthquake Engineering 43:202-212

McCormick J, Aburano H, Ikenaga M, Nakashima M Permissible residual deformation levels for building structures considering both safety and human elements. In: The 14th World Conference on Earthquake Engineering, Beijing, China, 2008.

McVerry GH From hazard maps to code spectra for New Zealand. In: 2003 Pacific Conference on Earthquake Engineering, Christchurch, NZ, 2003.

Porter KA, Kennedy RP, Bachman R (2006) Creating fragility functions for performance-based earthquake engineering Earthquake Spectra 23:471-489

Ramhormozian S, Clifton GC, MacRae GA The asymmetric friction connection with belleville springs in the sliding hinge joint. In: 2014 New Zealand Society for Earthquake Engineering Conference, Auckland, 2014.

Ramirez CM et al. (2012) Expected earthquake damage and repair costs in reinforced concrete frame buildings Earthquake Engineering and Structural Dynamics 41 doi:10.1002/eqe.2216

Ramirez CM, Miranda E (2012) Significance of Residual Drifts in Building Earthquake Loss Estimation Earthquake Engineering and Structural Dynamics 41:1477-1493 doi:10.1002/eqe.2217

Rawlinson \& Co (2015) Rawlinsons New Zealand construction handbook. Rawlhouse Publishing, Wellington, New Zealand

Retamales R, Davies R, Mosqueda G, Filiatrault A (2013) Experimental seismic fragility of cold-formed steel framed gypsum partition walls Journal of Structural Engineering 139:1285-1293

Standards Australia, Standards New Zealand (2002) NZS 1170.1:2002. Standards New Zealand, Wellington, New Zealand,

Standards Australia, Standards New Zealand (2011) AS/NZS 1170.2:2002. Standards New Zealand, Wellington, New Zealand

Standards New Zealand (1997) NZS 3404:1997. Standards New Zealand, Wellington, New Zealand,

Standards New Zealand (2002) NZS 1170.0:2002. Standards New Zealand, Wellington, New Zealand,

Standards New Zealand (2004) NZS 1170.5:2004. Standards New Zealand, Wellington, New Zealand,

Stirling MW et al. (2012) National seismic hazard model for New Zealand : 2010 update Bulletin of the Seismological Society of America 102:1514-1542 doi:10.1785/0120110170

Sullivan TJ (2016) Use of limit state loss versus intensity models for simplified estimation of expected annual loss Journal of Earthquake Engineering 20:954-974

US Resiliency Council (2015) USRC building rating system for earthquake hazards - implementation manual. USRC Technical Advisory Committee,

Zhao JX et al. (2006) Attenuation relations of strong ground motion in Japan using site classification based on predominant period Bulletin of the Seismological Society of America 96:898-913 